
\title{
25 Research Square \\ Possible Relationship between Korean Heat Wave and Western North Pacific Tropical Cyclone Genesis Frequency
}

\section{Yumi Cha}

National Institute of Meteorological Studies

JaeWon Choi

Pusan National University

Joong-Bae Ahn ( $\nabla$ jbahn@pusan.ac.kr)

Pusan National University https://orcid.org/0000-0001-6958-2801

\section{Research Article}

Keywords: Tropical cyclone genesis frequency, heat wave, East Asian summer monsoon, western North Pacific summer monsoon, Scandinavia teleconnection pattern

Posted Date: September 1st, 2021

DOI: https://doi.org/10.21203/rs.3.rs-474806/v2

License: (c) (i) This work is licensed under a Creative Commons Attribution 4.0 International License. Read Full License 


\section{Abstract}

This study conducted a correlation analysis between tropical cyclone genesis frequency (TCGF) in the western North Pacific (WNP) and heat wave days (HWD) in Korea during July and August for 46 years (1973-2018) and we found a strong positive correlation between them. This implied that the higher the TCGF in the WNP during July and August, the higher the HWD in Korea becomes. To examine the cause of the statistically significant positive correlation between the TCGF during July and August in the WNP and the HWD in Korea, 15 years with the highest frequency and the lowest frequency out of the 46 years in the TCGF time series were selected and defined as high TCGF years and low TCGF years, respectively. An analysis of the difference in $2 \mathrm{~m}$ air temperature (Air $2 \mathrm{~m}$ ) between the two groups showed that in the mid-latitude region of Asia, the Air2m was higher during the high TCGF years. Thus, it could be seen from this analysis that the increase of HWD during the high TCGF years is likely to occur in the entire midlatitude region of East Asia as well as in Korea. According to the difference in atmospheric circulations between the two groups, in all layers of the troposphere, anomalous anticyclonic and cyclonic circulations were strengthened in the mid-latitude region of East Asia and in the WNP, respectively, which was similar to the Pacific-Japan (PJ) teleconnection pattern. Furthermore, the anomalous anticyclone strengthened in the mid-latitude region of East Asia was associated with the weakening of the East Asian summer monsoon, and the anomalous cyclone strengthened in the WNP was associated with the WNP summer monsoon. The difference in the vertical meridional circulation averaged over the longitude range where Korea is located showed that anomalous upward and downward flows were strengthened in the WNP and in the latitude where Korea is located, respectively. This implied that the local Hadley circulation was strengthened during the high TCGF years. An analysis of the difference in the mean sea surface temperature during July and August showed that the eastern Pacific (EP) La Niña was strengthened during the high TCGF years. To determine the cause of the formations of anomalous anticyclones in the mid-latitude region of East Asia and in the WNP during the high TCGF years, the $500 \mathrm{hPa}$ wave activity flux was analyzed. The wave activity flux originated from the North Atlantic, passed through the Scandinavian Peninsula, the North coast of Russia, and East Siberia before reaching Korea and the WNP. This spatial distribution was similar to the Scandinavia teleconnection pattern. Therefore, we conclude that the anomalous anticyclone formed in the mid-latitude region of East Asia and the anomalous cyclone formed in the WNP during the high TCGF years are associated with the Scandinavia teleconnection pattern.

\section{Introduction}

Heat wave and tropical cyclone (TC) are representative meteorological disasters that cause serious damage to South Korea. According to the Annual Disaster Report for recent two years, the number of deaths due to heat wave was 48 in 2018 and 30 in 2019 (total deaths caused by meteorological disasters in each year were 53 and 48, respectively), recording the biggest casualty in South Korea. According to Kim et al. (2014), the average number of deaths by heat wave was 21 per year and the number of deaths by heat wave increased exponentially with the increase of the heat wave days during the last two 
decades. TC is also the second most damaging natural disasters after heat wave in South Korea. Moreover, because TCs are accompanied by destructive wind and heavy rainfall, even one TC event can cause enormous socioeconomic damage. In fact, TCs have long been the most devastating natural phenomenon on South Korea (Ministry of the Interior and Safety (MOIS), 2017; 2018; 2019).

The rise of global temperature and sea surface temperature (SST) is increasing severe weather phenomena such as heat wave and TC, which are likely to become more frequent in the future (IPCC, 2019). Consequently, the Asian region including South Korea is actively conducting related research, and there is concern that severe weather phenomena will be strengthened due to climate change. However, existing studies mostly research these two phenomena independently (heat wave: Choi et al., 2007; Park et al, 2008; Kim et al., 2009; Kim et al., 2016; Suh et al., 2016; Yeh et al., 2018; Shin et al., 2019, TC: Moon et al., 2018; Knutson et al., 2010; Chan et al., 2020; Choi et al., 2015). Mattews et al. (2019) pointed out the need for considering these two severe weather phenomena that occur in warm season. After conducting simulations by applying probabilistic simulation and climate change scenario using major TCs in Northwest Pacific, South Indian and North Atlantic basins and heat wave index, they found that compound TC-heat wave events are occurring often and predicted that their frequency would increase in the future. They also projected that a highly destructive sequence will result in the event of the successive effects of TCs and heat wave. Zhong et al. (2019) discovered through an analysis of TCs in the western North Pacific (WNP) and hot summer days in central eastern China that when TCs occurred more frequently, there were more hot days in the central eastern China. They insisted that this is a feedback effect between TC for western North Pacific subtropical high (WNPSH), which governs a wide area from central eastern China to the Pacific Ocean of eastern Japan, and hot summer days in central eastern China.

There have been few studies on the complex interaction between TC and heat wave in South Korea. However, the correlations of these two phenomena were estimated by previous studies (e.g. Lin 2019). TC is a meso-scale weather phenomenon, but the development of a TC depends on the effect of the surrounding large-scale or synoptic-scale environment after it occurs in the tropical western Pacific and moves north. Because the TC moves along the south edge of the WNPSH, therefore, the expansion of WNPSH is also an important factor in addition to the traditional factors affecting TCs in lower latitude (e.g., monsoon gyre/trough, high SST, easterly) (Cha et al. 2014). Furthermore, it has been demonstrated that large-scale patterns in the higher latitude such as Arctic Oscillation (AO), North Atlantic Oscillation (NAO), Pacific-Japan teleconnection (PJ) patterns influence the TC activities (Choi and Byun 2010; Zhou and Cui 2014; Choi et al. 2010; Kim et al. 2012; Choi and Moon 2012).

Heat wave also has been proven to develop through interactions with synoptic-scale weather events in many studies (Lee and Lee 2016; Lee et al. 2019; Yoon et al. 2018; Yeo et al. 2019; Choi et al. 2020). Lee et al. (2020a) analyzed extreme heat wave periods in 2016 and 2018 and showed that heat wave is closely related to WNPSH by demonstrating that heat wave started when the WNPSH moved north to the south sea of Korea and South Korea was under the influence of WNPSH. Yoon et al. (2018) and Lee et al. (2020b) distinguished three typical weather types that cause heat wave. Heat wave mainly occurred when 
the north edge of WNPSH was located in Korea, in particular. By contrast, heat waves caused by orographic effect were frequent and showed the lowest number of occurrence days in June (Lee et al. 2020b). Choi et al. (2020) and Lee et al. (2019) showed that teleconnection and global warming related to tropical convective activity contributed to heat waves in 2016. Lee and Lee (2016) showed that the deep convection phenomenon of South China Sea (SCS) provides a condition that causes heat wave through Rossby wave train, suggesting that tropical forcing is another major cause of heat wave.

In addition, we need to pay attention to the fact that both heat waves and TCs occur during the peak season of July and August. It is very unlikely to be actually affected by compound phenomena because South Korea is influenced by only 1 or 2 TCs in this season (only 4 TCs occurred in 1979-2017 in the study of Mattews et al. (2019) as well). However, unlike other seasons, most TCs that occur in July and August move north to the mid-latitude and the Northeast Asia, and cause indirect influence on the Korean Peninsula in various forms such as extreme wind, storm, and heavy rainfall even though they do not directly land in Korea (KMA 2011). Moreover, recently, the TC genesis/activity region has been found to gradually shift toward the north (Kossin et al. 2014; Moon et al. 2015; Choi et al., 2015). Thus, the possibility of TC directly or indirectly affecting the Korean Peninsula increases in a relatively short period of time after the TC genesis which should also be considered.

This study analyzed the correlation between tropical cyclone genesis frequency (TCGF) in the WNP and heat wave days (HWD) in Korea during July and August and investigated the cause in large-scale environments and atmospheric circulations. We suggest that heat wave and TC are closely correlated because both are influenced by summer synoptic pattern. Furthermore, since both are hazardous weather events that cause much damage, related research needs to be conducted to prepare for potential havoc in the future.

Section 2 introduces the data and analysis method. Section 3 presents the correlation between heat wave in Korea and TC genesis in the WNP and a possible mechanism. Finally, Sect. 4 summarizes the results of this study.

\section{Data And Methodology}

\subsection{Data}

This study used the data of the Regional Specialized Meteorological Center (RSMC)-Tokyo Typhoon Center to analyze TCs. In addition, to analyze large-scale environments and atmospheric circulation, the National Centers for Environmental Prediction/National Center for Atmospheric Research (NCEP/NCAR) Reanalysis dataset (Kalnay et al., 1996) was used. As for monthly global SST data, the National Oceanic and Atmospheric Administration (NOAA) Extended Reconstructed SST analysis (version 3) was used (Smith et al. 2008). The NOAA interpolated outgoing longwave radiation (OLR) was used to examine the state of convective activity (Liebmann B and Smith CA 1996). The precipitation data utilized is Global Precipitation Climatology Project (GPCP) version 2.3 (Adler et al. 2003). 
Furthermore, this study used the surface air temperature (SAT), precipitation, and Palmer Drought Severity Index (PDSI) data observed at 58 weather observation stations in Korea. This data can be obtained from the website of Korea Meteorological Administration (KMA) (https://www.kma.go.kr), and the spatial distributions of the 58 weather observation stations are shown in Fig. 1a. Since the Ulleungdo and Jeju regions show unique weather characteristics of islands, the observation data in these two regions were excluded from this study. Since the number of weather observation stations in Korea has rapidly increased since 1973, this study used data since 1973. The data of HWD and tropical night in Korea are officially provided on the KMA website (https://data.kma.go.kr/climate/). KMA defines HWD as the number of days with daily maximum temperatures of $33^{\circ} \mathrm{C}$ or higher, and tropical night days as the number of days with nighttime minimum temperatures of $25^{\circ} \mathrm{C}$ or higher. Since the HWD mainly appears high in July and August as shown in Fig. 1b, this study used July-August mean data.

This study also used the East Asian summer monsoon (EASM) index (EASMI) of Li and Zeng (2002, $2003,2005)$, and the western North Pacific summer monsoon (WNPSM) index (WNPSMI) provided on the website of the Asia-Pacific Data Research Center (APDRC) of the University of Hawaii (http://apdrc.soest.hawaii.edu/projects/monsoon/seasonal-monidx.html).

The Scandinavia teleconnection index is provided by the NOAA Climate Prediction Center (CPC) (https://www.cpc.ncep.noaa.gov/data/teledoc/scand.shtml).

In addition, the Niño-3 index provided by the NOAA Physical Sciences Laboratory (PSL) was used (https://psl.noaa.gov/gcos_wgsp/Timeseries/Nino3/).

\subsection{Methodology}

The two-tailed Student's t test was used to determine the significance of the results of this study (Wilks 1995). The horizontal components of Stationary Rossby wave propagation were calculated using the formula of Takaya and Nakamura (2001). The Pacific-Japan index is defined as a difference between two grid points $\left(40^{\circ} \mathrm{N}, 150^{\circ} \mathrm{E}\right.$ and $\left.25^{\circ}, 125^{\circ} \mathrm{E}\right)$ for $850 \mathrm{hPa}$ geopotential height anomalies (Wakabayashi and Kawamura 2004; Kawamura and Ogasawara 2006).

In this study, TC was defined as those that occurred in the WNP and developed stronger than tropical depression (TD). Furthermore, extratropical cyclone (EC) was also included in this study because it causes significant human and property damage in the mid-latitude region of East Asia after a TC is changed to an EC.

\section{Results}

\subsection{Relationship between heat wave days (HWD) in Korea and TC genesis frequency (TCGF) over the western North Pacific (WNP)}

Figure 2a shows the TCGF in the WNP and the time series of HWD in Korea during July and August. Both time series show distinct interannual variations rather than decadal variations. Meanwhile, the linear 
trend of the TCGF is statistically insignificant because it shows little change, but the HWD in Korea shows an increasing linear trend due to the effect of global warming. This increasing linear trend is significant at the $95 \%$ confidence level. A close observation of these two time-series reveals an in-phase trend between the two variables. Thus, a correlation analysis between the two variables shows a strong positive correlation of 0.57 . This correlation is significant at the $99 \%$ confidence level. This means that the higher the TCGF in the WNP during July and August, the higher the HWD in Korea. However, this correlation may change if the linear trend is removed from the two variables. Therefore, the correlation was analyzed again after removing the linear trend from the two variables. However, it did not show a significant difference from the original correlation (Corr $=0.55$, which is significant at the $99 \%$ confidence level). Furthermore, the correlation between tropical night in Korea and the TCGF in the WNP during July and August also shows a high correlation of 0.60 (not shown). This correlation is also significant at the $99 \%$ confidence level.

Meanwhile, to examine in more detail on the correlation between HWD in Korea and TCGF in the WNP during July and August, the WNP was divided into the following four areas (Fig. 3a): Northwest (NW) area, Southwest (SW) area, Northeast (NE) area, Southeast (SE) area. This distinction was based on $16^{\circ} \mathrm{N}$ and $141^{\circ} \mathrm{E}$, according to the average TC genesis location for 46 years. Among these four areas, the area that showed the highest correlation between TCGF and HWD in Korea during July and August is SE area with a correlation of 0.63 . This correlation is significant at the $99 \%$ confidence level. The next is NW area in which the TCGF during July and August in this area and the HWD in Korea have a correlation of 0.52. This correlation is also significant at the $99 \%$ confidence level. The correlation between the two variables in the other two regions is lower than 0.25 . This correlation in these two regions is significant at $90 \%$ confidence level. Consequently, the two variables tend to have a high correlation only in the NW and SE areas in the WNP. This appears to be because a monsoon trough develops from the northwest to southeast direction in the tropical and subtropical WNP in general, and TCs tend to occur along this monsoon trough (Matsuura et al. 2003).

Therefore, the time series of TCGF during July and August in the NW and SE areas were analyzed (Figs. 3b and 3c). The time series of TCGF in the NW area shows the lowest frequency in the late 2000s and tend to increase rapidly since 2010 (Fig. 3b), whereas the linear trend changed very little during the total analysis period of 46 years. However, when a correlation analysis was conducted after removing the linear trend from the two variables because the linear trend of the HWD tended to increase in Korea, it was not much different from the original correlation (Corr $=0.51$, which is significant at the $99 \%$ confidence level). The TCGF time series in the SE area has a strong interannual variation in general, but a weak interdecadal variation can be seen as well. They also show a rapidly increasing trend since the early 2010s (Fig. 3c). This time series also shows very little change in linear trend, and the correlation did not change even when the linear trend was removed from the two time series (Corr $=0.62$, which is significant at the $99 \%$ confidence level). 


\subsection{Spatiotemporal distribution of air temperature and rainfall}

To examine the reason for the high positive correlation between the TCGF during July and August in the WNP and the HWD in Korea, 15 years with the highest frequency in the TCGF time series in the WNP during July and August out of the 46 years and 15 years with the lowest frequency out of the 46 years were selected and defined as high TCGF years and low TCGF years, respectively (Table 1). The selected 30 years have a number of samples large enough to occupy about $70 \%$ of the total analysis period. Then the mean difference between high TCGF years and low TCGF years was analyzed. The mean HWD in Korea for 46 years is 10.9 days, and there are only four years among the high TCGF years that did not exceed this mean HWD $(1981,1989,1992,2002)$ and only four years among the low TCGF years that did not exceed this mean HWD $(1983,1995,2008,2010)$. Hence, the mean HWD of high TCGF years is 15.4 days, but the mean HWD of low TCGF years is only 8.0 days, and the difference in the mean HWD between the two groups is 7.4 days. This mean difference is significant at the $95 \%$ confidence level. 
Table 1

Heat wave days (HWD) in Korea in high tropical cyclone genesis frequency (TCGF) years and low TCGF years.

\begin{tabular}{|llll|}
\hline \multicolumn{3}{|l}{ High TCGF years } & \multicolumn{3}{l}{ Low TCGF years } \\
\hline Year & HWD & Year & HWD \\
\hline 1973 & 16.2 & 1975 & 10.0 \\
\hline 1978 & 17.0 & 1977 & 10.9 \\
\hline 1981 & 9.3 & 1979 & 5.9 \\
\hline 1989 & 4.7 & 1980 & 0.8 \\
\hline 1992 & 6.7 & 1983 & 11.3 \\
\hline 1994 & 31.1 & 1995 & 11.8 \\
\hline 1997 & 12.8 & 1998 & 2.6 \\
\hline 2000 & 12.4 & 2003 & 1.6 \\
\hline 2001 & 12.7 & 2007 & 9.8 \\
\hline 2002 & 5.9 & 2008 & 12.5 \\
\hline 2004 & 16.0 & 2009 & 4.2 \\
\hline 2013 & 18.5 & 2010 & 13.9 \\
\hline 2016 & 22.4 & 2011 & 7.5 \\
\hline 2017 & 14.4 & 2014 & 7.4 \\
\hline 2018 & 31.5 & 2015 & 10.1 \\
\hline Average & 15.4 & Average & 8.0 \\
\hline
\end{tabular}

Here, we examined the spatial distribution of the mean SAT in July and August for the two groups (left panel of Figs. $4 \mathrm{a}$ and $4 \mathrm{~b}$ ). The spatial distributions of the two groups appear similar in general. The northeast region in Korea shows the lowest SAT whereas the southeast inland and west inland areas show somewhat high SATs. However, most areas excluding the northeast region in high TCGF years show SATs higher than $30^{\circ} \mathrm{C}$ (left panel of Fig. 4a), whereas in low TCGF years, most areas in Korea show SATs lower than $30^{\circ} \mathrm{C}$ (left panel of Fig. 4b). The difference between the two groups shows positive anomaly in all areas in Korea (left panel of Fig. 4c), and the largest value in the central region of the east coast.

Meteorologically, this region is known to have relatively high temperatures during summer in the country (Ko et al. 2006). The daily time series of the difference between the two groups for SAT indicate that the high TCGF years have higher values from January to August whereas the low TCGF years have higher values from September to November (left panel of Fig. 4d). The largest variations in the SAT during the year appear in these two periods. 
The reason that the SAT is high (low) may be because there are few (many) clouds in the atmosphere and there is a low (high) possibility of precipitation. Hence, the spatial distribution of total rainfalls in July and August for the two groups were analyzed (right panel of Figs. 4a and 4b). As expected, the spatial distributions of the two groups appear similar overall. The rainfall is relatively large in the northern region of Korea, whereas the rainfall is low in the eastern region and the west coast region. During the high TCGF years, the rainfall in the northern region of Korea is only $600 \mathrm{~mm}$ (right panel of Fig. 4a), but during the low TCGF years, it is higher than $700 \mathrm{~mm}$ in the region (right panel of Fig. 4b). In particular, the rainfall in the eastern region of Korea is lower during the high TCGF years. The difference between the two groups shows negative anomaly in most areas excluding the northeast coastal region and part of the southeast coast region (right panel of Fig. 4c). This means that there were larger rainfalls during the low TCGF years than during the high TCGF years. The largest difference appears in the northeast and southeast regions of Korea. The daily time series of the difference in rainfall between the two groups showed strong negative anomaly during July and August, indicating that the HWD could increase in Korea during the high TCGF years (right panel of Fig. 4d).

\subsection{Large-scale environments and atmospheric circulations}

This study first analyzed the difference in $2 \mathrm{~m}$ air temperature (Air $2 \mathrm{~m}$ ) between the two groups in Asia (Fig. 5). In the mid-latitude region of East Asia $\left(30^{\circ}-40^{\circ} \mathrm{N}\right)$, the Air $2 \mathrm{~m}$ is higher during the high TCGF years, whereas the spatial distribution is higher during the low TCGF years in other regions. Thus, it can be seen from this analysis that the increase of HWD during the high TCGF years is likely to occur in the entire midlatitude region of East Asia as well as in Korea. Then the East Asia was divided into Northeast (NE) Asia area $\left(30^{\circ}-40^{\circ} \mathrm{N}, 115^{\circ}-140^{\circ} \mathrm{E}\right)$ and South China (SC) area $\left(20^{\circ}-30^{\circ} \mathrm{N}, 110^{\circ}-120^{\circ} \mathrm{E}\right)$. The time series of Air $2 \mathrm{~m}$ area-averaged in each region and the TCGF time series during July and August in the WNP are shown in Figs. $2 b$ and $2 c$. First, the Air $2 m$ time series area-averaged in the NE Asia area shows strong interannual variations and weak interdecadal variations (Fig. 2b). The linear trend of this time series shows an increasing linear trend, which is significant at the $95 \%$ confidence level. This increasing trend may be due to the effect of global warming. Furthermore, the two time series shows an in-phase trend, and the correlation between these two variables showed a positive correlation of 0.43 , which is significant at the $99 \%$ confidence level. This implies that if the TCGF in the WNP increases during July and August, there is a possibility that the HWD in the NE Asia area can increase as well. Since the two time series show a distinctly increasing linear trend, the correlation may be changed if the linear trend is removed from the two time series. Therefore, the correlation was reanalyzed after removing the trend from the two time series. As a result, the correlation became higher than the original correlation (Corr $=0.46$, which is significant at the $95 \%$ confidence level). The Air $2 \mathrm{~m}$ time series area-averaged in the SC area shows interannual and interdecadal variations (Fig. 2c). This time series also shows an increasing linear trend due to the effect of global warming, and this increasing linear trend is significant at the $95 \%$ confidence level. Furthermore, since these two time series show a trend of out-of-phase, the correlation between the two variables was analyzed. The result showed a negative correlation of -0.47 and this correlation is significant at the $99 \%$ confidence level. This indicates the possibility of decreasing HWD in the SC area where the TCGF increases during July and August in the WNP. When the correlation was reanalyzed after 
removing the linear trend from the two time series, the negative correlation was strengthened to some extent (Corr $=-0.49$, which is significant at the $99 \%$ confidence level).

Meanwhile, the differences in air temperature between the two groups were analyzed at lower-level (850 $\mathrm{hPa})$, middle-level (500 hPa), and upper-level (300 hPa) (left panel of Fig. 6). At $850 \mathrm{hPa}$, a warm anomaly is located in the mid-latitude region of East Asia, at the center of which Korea exists (left panel of Fig. 6a). The warm anomaly in Korea is significant at the $95 \%$ confidence level. In addition, a weak warm anomaly appears in the WNP in which TCs occur. Although weak, this warm anomaly must have influenced the increase of TCGF. At $500 \mathrm{hPa}$, a warm anomaly located in the mid-latitude region of East Asia was shifted further north (left panel of Fig. 6b). Thus, the southern region of Korea is included in the cold anomaly, but it is not statistically significant. In the WNP, the area of warm anomaly was also shifted to the north. At $300 \mathrm{hPa}$, the warm anomaly in the mid-latitude region of East Asia moved much further to the north and the entire Korea shows a cold anomaly (left panel of Fig. $6 \mathrm{c}$ ). The warm anomaly in the WNP is a little strengthened than at 850 and $500 \mathrm{hPa}$.

When both the relative humidity and air temperature are high when the air temperature is high, people tend to feel more uncomfortable. Thus, the difference in relative humidity between the two groups was analyzed (middle panel of Fig. 6). At all levels, a negative anomaly is located in the Korean Peninsula. This is believed to be due to the evaporation of water vapor as the subsidence was strengthened by the formation of anomalous anticyclone in Korea. Meanwhile, in the WNP where TCs were generated, the positive anomaly appears at every level. This is an important factor in increasing the TCGF. Gray (1975) pointed out relative humidity at lower-level and middle-level is one of the important factors among the six physical parameters that influence TC genesis.

To examine the variations of the spatial distributions of air temperature and relative humidity according to the level analyzed above, the differences in atmospheric circulations at the three levels were analyzed (right panel of Fig. 6). In all the layers of the troposphere, anomalous anticyclonic circulations are strengthened in the mid-latitude region of East Asia and anomalous cyclonic circulations are strengthened in the WNP. This is similar to the Pacific-Japan (PJ) teleconnection pattern (Nitta 1986, $1987,1989)$. The PJ pattern is an important pattern that influences the East Asian climate in summer (e.g., rainfall and air temperature) and TC genesis (Choi et al. 2010). Therefore, the correlations of the PJ index with the HWD in Korea and the TCGF in the WNP during July and August were analyzed (not shown). The results showed positive correlations of 0.43 and 0.41 , respectively, and these correlations were significant at the $99 \%$ confidence level. This suggests that in Korea, subsidence developed and water vapors evaporated with the strengthening of the anomalous anticyclone, resulting in negative relative humidity at every level. Moreover, as it moves from the lower level to the upper level, the anomalous anticyclone in the mid-latitude of East Asia is shifted to the north. Consequently, as analyzed above, the warm anomaly in the mid-latitude region of East Asia was shifted to the north toward the upper level. Meanwhile, the anomalous cyclone strengthened in the WNP at the three levels became an important background in the increase of TCGF. 
The increase or decrease of HWD in Korea is associated with the locations of western North Pacific subtropical high (WNPSH) and Tibetan high (TH) (Wu et al. 2012). Hence, the degree of development of WNPSH and TH was analyzed for the two groups (left panel of Fig. 7). Here, WNPSH (red line) and TH (blue line) are defined as areas larger than $5,870 \mathrm{gpm}$ and 12,480 gpm. The WNPSH is strengthened northwest to the western sea of Korea during the high TCGF years (left panel of Fig. 6a), whereas during the low TCGF years, it is expanded southwest to the southeastern region of China (left panel of Fig. 6b). TH is located a little north in the high TCGF years than in the low TCGF years, and is further expanded to the east during the low TCGF years. Hence, two high pressure systems are overlapped in Korea in high TCGF years. Thus, it can be seen that the HWD increased as the solar radiation increased due to the strengthening of subsidence as the high pressure systems were located in the upper and lower layers of the troposphere in Korea. Furthermore, during the high TCGF years, the two high pressure systems shifted to the north and low pressure systems were strengthened in the WNP, thus increasing the TCGF.

To examine this, the $850 \mathrm{hPa}$ geopotential height mean field was analyzed for the two groups (right panel of Fig. 7). Here, the dashed and solid lines indicate the monsoon trough and the ridge of WNPSH. The ridge of WNPSH is expanded northwest to the northeastern region of China in high TCGF years (right panel of Fig. 7a), but in low TCGF years, it is expanded west to the eastern coast of central China (right panel of Fig. 7b). As a result, in the high TCGF years when the ridge of WNPSH is shifted more to the north, the monsoon trough is strengthened east to $145^{\circ} \mathrm{E}$ (right panel of Fig. 7a). By contrast, in the low TCGF years, the monsoon trough is weakened only to $130^{\circ} \mathrm{E}$. This suggests that the strengthening of the ridge of WNPSH and monsoon trough in high TCGF years is associated with the increase of HWD in Korea and the increase of TCGF in the WNP during July and August.

\subsection{Local Hadley circulation}

Meanwhile, the anomalous anticyclone strengthened in the mid-latitude region of East Asia and the anomalous cyclone strengthened in the WNP can be associated with local Hadley circulation. To examine this, the difference in the vertical meridional circulation averaged over the longitude range of $120^{\circ}-130^{\circ} \mathrm{E}$ where Korea is located was analyzed (Fig. 8a). Anomalous upward flows are strengthened at $10^{\circ}-30^{\circ} \mathrm{N}$ where the WNP is located and anomalous downward flows are strengthened at $30^{\circ}-40^{\circ} \mathrm{N}$ where Korea is located. In particular, the center of anomalous upward motion in the WNP is located at $10^{\circ}-20^{\circ} \mathrm{N}$, and this is significant at the $95 \%$ confidence level. Furthermore, the center of anomalous downward motion at $30^{\circ}-40^{\circ} \mathrm{N}$ is distributed at $30^{\circ}-35^{\circ} \mathrm{N}$ where South Korea is located, which is placed in a region of the $95 \%$ confidence level. This anomalous vertical structure between the WNP and Korea means that the air rising in the WNP subsides in Korea. Therefore, the TCGF can increase in the WNP and can be an important background in which the HWD can increase in Korea. As a result of this, in the vertical structure of air temperature, a warm anomaly appears in the lower level of $30^{\circ}-40^{\circ} \mathrm{E}$ where Korea is located, and in the higher level, a cold anomaly appears (Fig. 8b). This result is consistent with the result in Fig. 6, which showed that the warm anomaly in the mid-latitude region of East Asia is shifted to the north toward the upper level. In the vertical structure of relative humidity, a negative anomaly appears in every level of the latitude range of Korea, and this characteristic is also consistent with the result in Fig. 6 (Fig. 8c). 
This local Hadley circulation that developed in high TCGF years can be also seen in the analysis of the differences in the horizontal divergence at lower and upper levels between the two groups (Fig. 9). At 850 $\mathrm{hPa}$, a negative anomaly appears in the WNP and a positive anomaly appears in the longitude range of $20^{\circ}-30^{\circ} \mathrm{N}$ (Fig. 9a). This means that anomalous convergence is strengthened in the WNP and anomalous divergence is strengthened at $20^{\circ}-30^{\circ} \mathrm{N}$. However, Korea shows a weak negative anomaly. At $300 \mathrm{hPa}, \mathrm{a}$ positive anomaly is strengthened in the WNP and a negative anomaly is located in the longitude range of $30^{\circ}-35^{\circ} \mathrm{N}$ where South Korea is located (Fig. 9b). This implies that anomalous divergence is strengthened in the WNP and anomalous convergence is strengthened in the mid-latitude region of East Asia. Thus, such a structure of horizontal divergence formed in the lower and upper levels implies that the air rising in the WNP falls in the mid-latitude region of East Asia, and this indicates that local Hadley circulation is strengthened in high TCGF years.

In summer, the higher the HWD, the lower the precipitation becomes, which can cause a drought. Thus, the mean PDSI in Korea during July and August and the time series of HWD in Korea were analyzed (Fig. 10a). A smaller PDSI implies a worse drought. The time series of the PDSI has strong interannual variations and the drought has worsened until recently due to the effect of climate change. This linear trend is significant at the $95 \%$ confidence level. Meanwhile, there is a distinct in-phase trend between the two variables. An analysis of the correlation between the two variables shows a high negative correlation of -0.60 . This high negative correlation is significant at the $99 \%$ confidence level. This means that in Korea, drought worsens as the HWD increases. The two time series show a distinct change in the linear trend, but the correlation did not show a significant difference from the original correlation even when the linear trend was removed from the two time series (Corr $=-0.58$, which is significant at the $99 \%$ confidence level). In addition, the mean PDSI during July and August in Korea and the time series of TCGF in the WNP during July and August were analyzed (Fig. 10b). There is a distinct out-of-phase trend between the two variables. Therefore, the correlation between the two variables was analyzed and it showed a negative correlation of -0.46 . This correlation is significant at the $99 \%$ confidence level. This indicates that an increase of TCGF in the WNP strengthens drought in Korea, and this result is associated with the local Hadley circulation as analyzed above.

\subsection{EASM and WNPSM}

The anomalous anticyclone strengthened in the mid-latitude region of East Asia and the anomalous cyclone strengthened in the WNP can be associated with EASM and WNPSM, respectively. Hence, the time series of the HWD in Korea and the mean EASMI and WNPSMI during July and August were analyzed (Figs. 11a and 11b). The HWD in Korea and the EASMI showed an opposite trend. When the correlation between the two variables was analyzed, the result showed a negative correlation of -0.57 (Fig. 11a). This correlation is significant at the $99 \%$ confidence level. This implies that as the EASM is strengthened (weakened), the HWD in Korea becomes lower (higher). The linear trend of the EASMI shows little change. Consequently, the correlation did not show a significant difference from the original correlation even when the linear trend was removed from the two time series (Corr $=-0.56$, which is significant at the $99 \%$ confidence level). The time series of the HWD in Korea and the mean WNPSMI 
during July and August were also analyzed (Fig. 11b). The two variables showed a distinct in-phase trend. When the correlation was analyzed, it showed a positive correlation of 0.56 . This correlation is significant at the $99 \%$ confidence level. The WNPSMI has shown an increasing linear trend until recently, and this increasing linear trend is significant at the $90 \%$ confidence level. Therefore, the correlation was reanalyzed after removing the linear trend from the two time series, and it did not show a significant difference from the original correlation (Corr $=0.58$, which is significant at the $99 \%$ confidence level). The above result suggests that the anomalous anticyclone strengthened in the mid-latitude region of East Asia during high TCGF years implies weakening of the EASM, and the anomalous cyclone strengthened in the WNP implies the strengthening of the WNPSM. Regarding this, Choi et al. (2016) have found that when the WNPSM is strengthened, the TCGF increases, but the EASM tends to be weakened.

To examine whether the EASM was weakened in the mid-latitude region of East Asia during high TCGF years and whether the WNPSM was strengthened in the WNP, the differences in the mean OLR, total cloud cover, and rainfall during July and August were analyzed (Figs. 11c, 11d, and 11e). In the analysis result of OLR, a negative anomaly appears in the WNP, whereas a positive anomaly appears in the mid-latitude region of East Asia (Fig. 11a). In particular, the center of positive anomaly in the mid-latitude region of East Asia is located in the zonal direction from the central eastern China to Korea and Japan. The positive anomaly in this region is significant at the $95 \%$ confidence level. From the above result, it can be seen that convective activity is strengthened in the WNP whereas the convective activity is weakened in the mid-latitude region of East Asia. As a result, a large amount of clouds is observed in the WNP regarding the total cloud cover and a negative anomaly appears in the mid-latitude region of East Asia (Fig. 11d). The negative anomaly in Korea is significant at the $95 \%$ confidence level. The large amount of clouds formed by the strengthening of convective activity in the WNP leads to a large amount of rainfalls, and the opposite characteristic appears in the mid-latitude region of East Asia (Fig. 11e).

\subsection{ENSO}

Meanwhile, to examine whether the El Niño-Southern Oscillation (ENSO) influences the HWD in Korea, the difference in the mean SST during July and August between the two groups was analyzed (Fig. 12a). In general, a strong cold anomaly appeared in the equatorial eastern Pacific, and this implies that the eastern Pacific (EP) La Niña strengthened during the high TCGF years. When the analysis result of the difference in velocity potential at lower and upper levels is examined, at the lower level, the center of anomalous convergence is located in the east-west direction from the eastern sea of Australia to the offshore of Peru. At the upper level, the center of anomalous divergence is located in subtropical and tropical central pacific (Figs. 12b and 12c). Therefore, the correlation between the Niño-3 index and the HWD in Korea was analyzed (not shown). These two variables showed a negative correlation of -0.25 at the $90 \%$ confidence level. However, the correlation analysis between the Niño-3 index and the TCGF in the WNP during July and August showed a negative correlation of -0.17 , which is statistically insignificant. Thus, a partial correlation analysis was conducted to examine whether the ENSO influenced the high positive correlation between HWD in Korea and TCGF in the WNP during July and August (Table 2). When the Niño-3 index was set as a control variable, the HWD in Korea and the TCGF in the WNP during July 
and August showed a positive correlation of 0.50 . This correlation was significant at the $99 \%$ confidence level. This result suggests that the effect of ENSO on the high positive correlation between the two variables is small.

Table 2

Statistical result of partial correlation analysis.

\begin{tabular}{|llll|}
\hline Control variable & Correlation variable & HWD & TCGF \\
\hline Nino 3 index & HWD & 1.0 & 0.50 \\
\cline { 2 - 4 } & TCGF & 0.50 & 1.0 \\
\hline
\end{tabular}

\subsection{Scandinavia teleconnection pattern}

To determine the cause of the formation of anomalous anticyclone in the mid-latitude region of East Asia and the formation of anomalous cyclone in the WNP during the high TCGF years, the $500 \mathrm{hPa}$ wave activity flux was analyzed (Fig. 13a). The wave activity flux originates from the North Atlantic passes through the Scandinavian Peninsula, the North coast of Russia and East Siberia before reaching Korea and the WNP. The analysis of the difference in the $500 \mathrm{hPa}$ geopotential height between the two groups shows a positive anomaly in the western sea of the UK, the Scandinavian Peninsula, northwestern coast of Russia, and the regions from Central Asia to the Bering Sea (shading in Fig. 13a). This spatial distribution is similar to the Scandinavia teleconnection pattern. Therefore, it can be seen that the anomalous anticyclone formed in the mid-latitude region of East Asia and the anomalous cyclone formed in the WNP during the high TCGF years are associated with the Scandinavia teleconnection pattern. To examine whether the HWD in Korea and the TCGF during July and August are associated with the Scandinavia teleconnection pattern, the Scandinavia index and the time series between the two variables were analyzed (Figs. 13b and 13c). Both variables showed an in-phase trend with the Scandinavia index. The Scandinavia index showed a significant positive correlation of 0.45 with the HWD in Korea at the 99\% confidence level (Fig. 13b). The correlation analysis with the TCGF in the WNP during July and August showed a positive correlation of 0.49 at the $99 \%$ confidence level (Fig. 13c). This shows that when the Scandinavia teleconnection pattern is strengthened, the HWD in Korea and the TCGF in the WNP during July and August are increased.

\subsection{TC activity}

TCs can also influence the HWD in Korea in summer. Therefore, the differences in the TCGF and TC passage frequency (TCPF) during July and August between the two groups were analyzed (Figs. 14a and 14b). The spatial distribution of the TCGF shows a higher genesis frequency during high TCGF years in general (Fig. 14a). In particular, significantly large differences at the $95 \%$ confidence level appear in the South China Sea (SCS) and the northeastern sea of the WNP. The SCS and the northeast seas of WNP show significantly large differences at the $95 \%$ confidence level. Meanwhile, the spatial distribution of the TCPF (Fig. 14b) shows the spatial distribution of a dipole pattern. In other words, a negative anomaly appears in the Indochina Peninsula and SCS and the southeast region of China, and a positive anomaly 
in the remaining areas. The cause of such a difference in spatial distribution of the TCGF difference between the two groups can be seen from the analysis result of the difference in the $500 \mathrm{hPa}$ stream flow between the two groups (right panel of Fig. 6b). In the Indochina Peninsula, SCS and the southeastern region of China, anomalous northerlies are strengthened by anomalous cyclonic circulation formed in the WNP. These anomalous northerlies can play the role of steering flows that block TCs that move toward this area. By contrast, the mid-latitude region of East Asia including Korea is influenced by anomalous southeasterlies due to anomalous anticyclonic circulation, and these anomalous southeasterlies, which play the role of steering flows that move TCs to this region. This trend is associated with the location of WNPSH for the two groups (left panel of Fig. 7). TCs generally tend to move along the western edge of WNPSH. Since the WNPSH is extended in the northwest to the western sea of Korea. Thus, TCs can easily move toward Korea and the mid-latitude region of East Asia. By contrast, during the low TCGF years, the WNPSH is extended southwest toward the southern eastern China, and TCs move to the Indochina Peninsula, SCS and the southeast region of China. Therefore, the time series of the HWD in Korea and the TCPF in the SC area were analyzed (Figs. 14c and 14d). The TCPF in Korea shows an in-phase trend with the HWD in Korea (Fig. 14C), whereas it shows an out-of-phase trend with the TCPF in the SC area

(Fig. 14d). In particular, the TCPF in Korea shows a decreasing linear trend, which is significant at the $90 \%$ confidence level. According to the correlation analysis, the HWD in Korea and the TCPF in Korea shows a significant positive correlation of 0.42 at the $99 \%$ confidence level, whereas the HWD in Korea and the TCPF in the SC area shows a significant negative correlation of -0.51 at the $99 \%$ confidence level.

Therefore, it can be seen that the TCPF in Korea increases, but it decreases in the SC area during the high TCGF years. Consequently, even if the TCPF in Korea increased during the high TCGF years, it could not have contributed to mitigating the heat wave.

\section{Summary And Conclusions}

This study analyzed the correlations between the TCGF in the WNP and HWD in Korea during July and August for 46 years (1973-2018). The correlation analysis between these two variables showed a strong positive correlation. This implied that the higher the TCGF in the WNP during July and August, the higher the HWD in Korea became. Furthermore, the tropical night in Korea and the TCGF in the WNP during July and August also showed a high correlation.

Meanwhile, to examine in more detail the correlation between HWD in Korea and TCGF in the WNP during July and August, the WNP was divided into the following four areas: Northwest (NW) area, Southwest (SW) area, Northeast (NE) area, Southeast (SE) area. Among these four areas, the area that showed the highest correlation between TCGF and HWD in Korea during July and August is SE area, followed by the NW area. However, the two variables showed a low correlation in the other two regions.

To examine the cause of the high positive correlation between the TCGF in the WNP during July and August and the high HWD in Korea from the above analysis results, 15 years with the highest frequency in the TCGF time series in the WNP during July and August out of the 46 years and 15 years with the lowest frequency out of the 46 years were selected and defined as high TCGF years and low TCGF years, 
respectively. An analysis of the difference in Air2m between the two groups in Asia showed that in the mid-latitude region, the Air2m was higher during the high TCGF years, whereas the spatial distribution was higher during the low TCGF years in other regions. Thus, it could be seen from this analysis that the increase of HWD during the high TCGF years is likely to occur in the entire mid-latitude region of East Asia as well as in South Korea.

The differences in the air temperature at the lower, middle, and upper levels of the troposphere between the two groups were analyzed. At the lower level, the warm anomaly was located in the mid-latitude region of East Asia at the center of which Korea located. Furthermore, the WNP, which was the area of TC genesis showed a weak warm anomaly. At the middle level, the warm anomaly in the mid-latitude region of East Asia was shifted more to the north, and the area of the warm anomaly in the WNP was also shifted to the north. At the upper level, the warm anomaly in the mid-latitude region of East Asia moved much further to the north and the entire Korea shows a cold anomaly. In the WNP, the warm anomaly is more strengthened at the lower and middle levels. In addition, the differences in relative humidity between the two groups were analyzed. At all levels, Korea showed a negative anomaly. The reason of this was that subsidence was strengthened by the formation of anomalous anticyclone in Korea and evaporation had increased. By contrast, the WNP, which is a TC genesis area, showed a positive anomaly at every level.

The differences in atmospheric circulations between the two groups were analyzed. In all levels of the troposphere, anomalous anticyclonic and cyclonic circulations were strengthened in the mid-latitude region of East Asia and in the WNP, respectively. This was similar to the Pacific-Japan (PJ) teleconnection pattern (Fig. 15a). Furthermore, the anomalous anticyclone and cyclone strengthened in the mid-latitude region of East Asia and in the WNP was associated with the weakening of the EASM and the strengthening of the WNPSM, respectively.

The degrees of WNPSH and TH development were analyzed for the two groups. The WNPSH was strengthened northwest to the western sea of Korea during high TCGF years, whereas it was extended southwest to the southeastern region of China during the low TCGF years. TH moved further north during the high TCGF years than during the low TCGF years. Instead, it was further extended east during the low TCGF years. Therefore, during the high TCGF years, two high pressure systems were overlapped in Korea. Thus, high pressure systems were located at the lower and upper levels in Korea, and the strengthening of subsidence increased solar radiation, resulting in a higher HWD. Furthermore, during the high TCGF years, two high pressure systems were shifted north, which strengthened the low pressure system in the WNP, thus increasing the TCGF.

An analysis of the difference in the vertical meridional circulation averaged over the longitude range over Korea showed that anomalous upward and downward flows were strengthened in $10^{\circ}-30^{\circ} \mathrm{N}$ where the WNP is located and in $30^{\circ}-40^{\circ} \mathrm{N}$ where Korea is located, respectively. This anomalous vertical structure implied that the air rising in the WNP subsided in Korea and the local Hadley circulation was strengthened during the high TCGF years. 
The differences in the mean SST during July and August between the two groups were analyzed. In general, a cold anomaly appeared in the equatorial eastern Pacific, which implied the strengthening of the eastern Pacific (EP) La Niña during the high TCGF years. Consequently, a partial correlation analysis was conducted to examine whether the ENSO influenced the high positive correlation between the HWD in Korea and the TCGF in the WNP during July and August. When the Niño-3 index was set as a control variable, the HWD in Korea and the TCGF in the WNP during July and August showed a high positive correlation. This result suggested that the influence of ENSO on the high positive correlation between the two variables is small.

To determine the cause of the formation of anomalous anticyclone in the mid-latitude region of East Asia and the formation of anomalous cyclone in the WNP during the high TCGF years, the $500 \mathrm{hPa}$ wave activity flux was analyzed (Fig. 15b). The wave activity flux originated from the North Atlantic, passed through the Scandinavian Peninsula, the North coast of Russia, and East Siberia before reaching Korea and the WNP. The differences in the $500 \mathrm{hPa}$ geopotential height between the two groups showed a positive anomaly in the western sea of the UK, the Scandinavian Peninsula, the northwestern sea of Russia, and the areas from Central Asia to the Bering Sea. This spatial distribution was similar to the Scandinavia teleconnection pattern. Therefore, it could be seen that the anomalous anticyclone formed in the mid-latitude region of East Asia and the anomalous cyclone formed in the WNP during the high TCGF years are associated with the Scandinavia teleconnection pattern.

The differences in the TCPF during July and August between the two groups were analyzed. The Indochina Peninsula, SCS, and the southeastern region of China showed a negative anomaly, whereas the other regions showed a positive anomaly. This result suggests that during the high TCGF years, the TCPF it could not contribute to mitigating the heat wave even if the TCPF increased in Korea.

\section{Declarations}

\section{Acknowledgements}

This work was funded by the Korea Meteorological Administration Research and Development Program " Enhancement of Convergence Technology of Analysis and Forecast on Severe Weather " under Grants (KMA2018-00121)

\section{References}

1. Adler RF, Huffman GJ, Chang A, Ferraro R, Xie P, Janowiak J, Rudolf B, Schneider U, Curtis S, Bolvin D, Gruber A, Susskind J, Arkin P, Nelkin E (2003) The Version-2 Global Precipitation Climatology Project (GPCP) Monthly Precipitation Analysis (1979-Present). J Hydrometeorol 4:1147-1167

2. Cha Y, Choi KS Chang KH, Lee JY, Shin DS (2014) Characteristics of the changes in tropical cyclones influencing the South Korean region over the recent 10 years (2001-2010). Natural Hazards 74:

$1729-1741$

Page $17 / 35$ 
3. Chan CLJ (2000) Tropical Cyclone Activity over the Western North Pacific Associated with El Niño and La Niña Events. J Clim 13: 2960-2972

4. Choi KS, Byun HR (2010) Possible relationship between western North Pacific tropical cyclone activity and Arctic oscillation. Theor Appl Climatol 100: 261-274

5. Choi KS, Park KJ, Kim JY, Kim BJ (2015) Synoptic Analysis on the Trend of Northward Movement of Tropical Cyclone with Maximum Intensity. J Environ Sci 36: 171-180 (In Korean)

6. Choi JW, Kim BJ, Zhang RH, Park KJ, Kim JY, Cha Y, Nam JC (2016) Possible relation of the western North Pacific monsoon to the tropical cyclone activity over the western North Pacific. Int. J. Climatol 36:3334-3345

7. Choi KS, Wu CC, Cha EJ (2010) Change of tropical cyclone activity by Pacific-Japan teleconnection pattern in the western North Pacific. J Geophys Res 115 D19114

8. Choi N, Lee MI (2019) Spatial variability and long-term trend in the occurrence frequency of heatwave and tropical night in Korea. Asia-Pacific J Atmos Sci 55: 101-114

9. Choi N, Lee MI, Cha DH (2020) Decadal Changes in the Interannual Variability of Heat Wave in East Asia Caused by Atmospheric Teleconnection Changes. J Clim 33: 1505-1522.

10. Gray, W.M. Tropical cyclone genesis. Dept. of Atmospheric Science Paper 234, Colorado State University, Fort Collins, CO, 1975, 121 pp.

11. IPCC, 2019: Climate Change and Land: an IPCC special report on climate change, desertification, land degradation, sustainable land management, food security, and greenhouse gas fluxes in terrestrial ecosystems [P.R. Shukla, J. Skea, E. Calvo Buendia, V. Masson-Delmotte, H.-O. Pörtner, D. C. Roberts, P. Zhai, R. Slade, S. Connors, R. van Diemen, M. Ferrat, E. Haughey, S. Luz, S. Neogi, M. Pathak, J. Petzold, J. Portugal Pereira, P. Vyas, E. Huntley, K. Kissick, M. Belkacemi, J. Malley, (eds.)]. In press. 874pp.

12. Kalnay E, Kanamitsu M, Kistler R et al (1996) The NCEP/NCAT 40-year reanalysis project. Bull Am Meteorol Soc 77:437-471

13. Kawamura R, Ogasawara T (2006) On the Role of Typhoons in Generating PJ Teleconnection Patterns over the Western North Pacific in Late Summer. SOLA 2: 37-40

14. Ko JW, Baek HJ, Kwon WT, Park JY (2006) The characteristics of spatial distribution of temperature and regionalization in Korea. Journal of Climate Research 1:3-14

15. Kim DW, Jung JH, Lee JS (2014) Characteristics of Heat wave Mortality in Korea. Atmosphere 24(2): 225-234 (In Korean)

16. Kim JA, Kim KR, Lee CC, Sheridan SC, Kalkstein LS, Kim BJ (2016) Analysis of Occurrence Distribution and Synoptic Pattern of Future Heat Waves in Korea., Journal of Climate Research, 11(1): 15-27 (In Korean)

17. Kim JS, Cheuk R, Li Y, Zhou W (2012) Effects of the Pacific-Japan teleconnection pattern on tropical cyclone activity and extreme precipitation events over the Korean peninsula. J Geophys Res, 117: D18109, 1-10 
18. Korea Meteorological Administration (KMA) (2011) Typhoon White Book, pp. 358.

19. Knutson TR, McBride JL, Chan CLJ, Emanuel K, Holland G, Landsea C, Held I, Kossin JP, Srivastava AK, Sugi M (2010) Tropical cyclones and climate change. Nature Geoscience 3: 157-163

20. Kossin JP, Emanuel KA, Vecchi GA (2014) The poleward migration of the location of tropical cyclone maximum intensity Nature 509; 349-352

21. Lee HD, Min KH, Bae JH, Cha DH (2020) Characteristics and Comparison of 2016 and 2018 Heat Wave in Korea, Atmosphere 30(1): 1-15 (In Korean)

22. Lee WS, Lee MI (2016) Interannual variability of heat waves in South Korea and their connection with large-scale atmospheric circulation patterns. Int J Climatol 36: 4815-4830

23. Lee HC, Cho YJ, Lim BH, Kim SB (2020) Study on the Association of Casualties and Classification of Heat Wave Weather Patterns in South Korea Using K-Means Clustering Analysis., J Korean Soc Hazard Mitig 20(3): 11-18 (In Korean)

24. Lee JY, Kim HJ, Jeong YR (2019) Influence of Boreal Summer Intraseasonal Oscillation on the 2016 Heat Wave over Korea. Atmosphere 29(5): 627-637 (In Korean)

25. Li JP, Zeng QC (2002) A unified monsoon index. Geophys Res Lett 29:1274, doi:10.1029/2001GL013874

26. Li JP, Zeng QC (2003) A new monsoon index and the geographical distribution of the global monsoons. Adv Atmos Sci 20:299-302

27. Li JP, Zeng QC (2005) A new monsoon index, its interannual variability and relation with monsoon precipitation. Climatic and Environmental Research 10:351-365

28. Liebmann B, Smith CA (1996) Description of a Complete (Interpolated) Outgoing Longwave Radiation Dataset. Bull Am Meteorol Soc 77:1275-1277

29. Lin N (2019) Tropical cyclones and heatwaves. Nature-Clim Change 9: 578-580

30. Matsuura T, Yumoto M, lizuka S (2003) A mechanism of interdecadal variability of tropical cyclone activity over the western North Pacific. Clim Dyn 21:105-117

31. Mattews T, Wilby RL, Murphy C (2019) An emerging tropical cyclone-deadly heat compound hazard, Nat. Clim. Change, https://doi.org/10.1038/s41558-019-0525-6

32. Ministry of the Interior and Safety (MOIS) (2017) Annual Disaster Report, p 147

33. Ministry of the Interior and Safety (MOIS) (2018) Annual Disaster Report, p 217

34. Ministry of the Interior and Safety (MOIS) (2019) Annual Disaster Report, p156

35. Moon IJ, Kim SH, Chan JCL (2019) Climate change and tropical cyclone trend. Nature 570: E3-E5

36. Moon IJ, Kim SH, Klotzbach P, Chan JCL (2015) Roles of interbasin frequency changes in the poleward shifts of the maximum intensity location of tropical cyclones. Environ Res Lett 10: 10400

37. Ning L (2019) Tropical and cyclones and heatwaves, Nature Climate Change 9: 579-580

38. Nitta T (1986) Long-term variations of cloud amount in the western Pacific region. J Meteorol Soc Jpn 64:373-390 
39. Nitta T (1987) Convective activities in the tropical western Pacific and their impact on the Northern Hemisphere summer circulation. J Meteorol Soc Jpn 65:373-390

40. Nitta T (1989) Global features of the Pacific-Japan oscillation. Meteorol Atmos Phys 41:5-12, doi:10.1007/BF01032585

41. Shin J, Olson R, An SI (2018) Projected heat wave characteristics over the Korean peninsula during the twenty-first century. Asia-Pacific J Atmos Sci 54(1): 53-61

42. Smith TM, Reynolds RW, Peterson TC, Lawrimore J (2008) Improvements to NOAA's historical merged Land-Ocean surface temperature analysis (1880-2006). J Clim 21:2283-2296

43. Takaya K, Nakamura H (2001) A formation of a phase-independent wave-activity flux for stationary and migratory quasigeosttrophic eddies on a zonally varying basic flow. J Atmos Sci 58:608-627

44. Wakabayashi S, Kawamura R (2004) Extraction of Major Teleconnection Patterns Possibly Associated with the Anomalous Summer Climate in Japan. Journal of the Meteorological Society of Japan 82:1577-1588

45. Wilks DS (1995) Statistical methods in the atmospheric sciences. Academic Press, 467 pp.

46. Wu Z, Jiang Z, Li J, Zhong S, Wang L (2012) Possible association of the western Tibetan Plateau snow cover with the decadal to interdecadal variations of northern China heatwave frequency. Clim Dyn 39:2393-2402

47. Yeh SW, Won YJ, Hong JS, Lee KJ, Kwon M, Seo KH, Ham YG (2018) The record-breaking heat wave in 2016 over South Korea and its physical mechanism. Mon Wea Rev 146: 1463-1474, doi:10.1175/MWR-D-17-0205.1

48. Yeo, SR, Yeh SW, Lee WS (2019) Two types of heat wave in Korea associated with atmospheric circulation pattern. J Geophy Res-Atmos 124: 7498-7511

49. Zhong Z, Chen X, Yang XQ, Ha Y, Sun Y (2019) The relationship of frequent tropical cyclone activities over the western North Pacific and hot summer days in central-eastern China. Theore Appl Climatol 138: $1395-1404$

50. Zhou BT, Cui X (2014) Interdecadal change of the linkage between the North Atlantic Oscillation and the tropical cyclone frequency over the western North Pacific. Science China Earth Sciences, 57: 2148-2155

\section{Figures}


(a) Station and topo

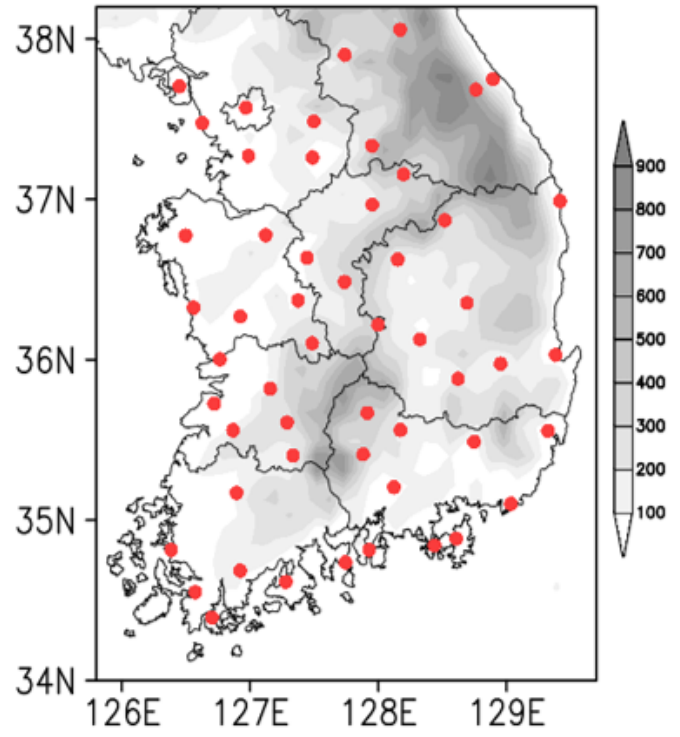

(b) Monthly variation of HWD in Korea

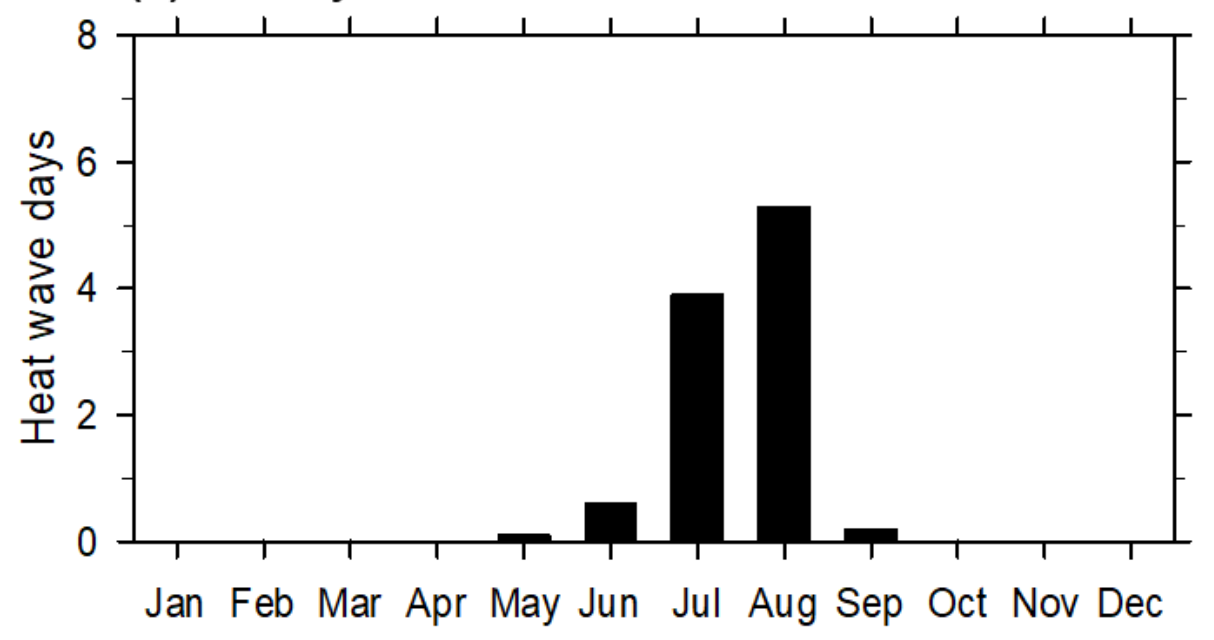

Figure 1

(a) spatial distribution of observation station and (b) monthly variation of heat wave days (HWD) in Korea. 


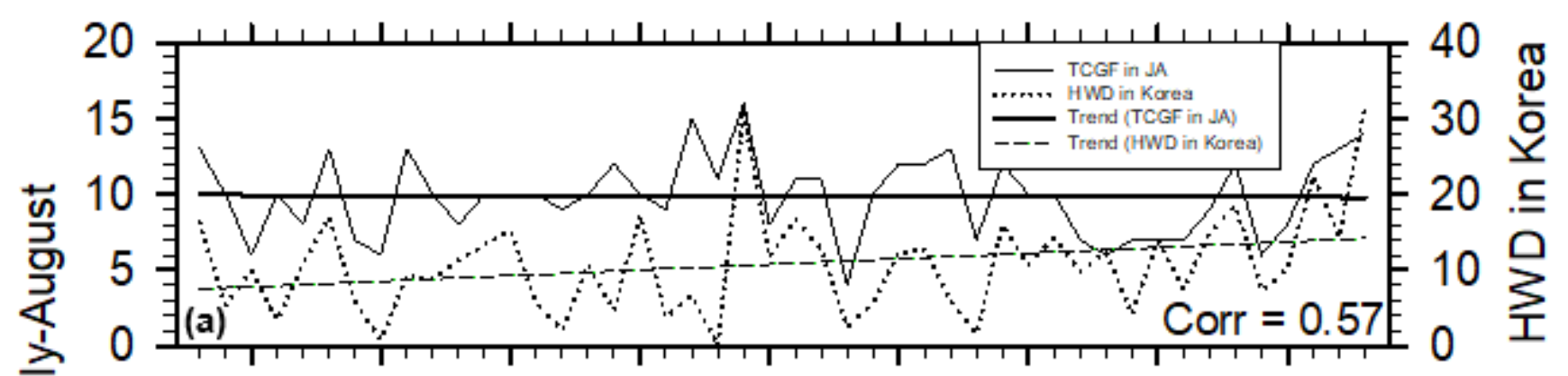

197519801985199019952000200520102015
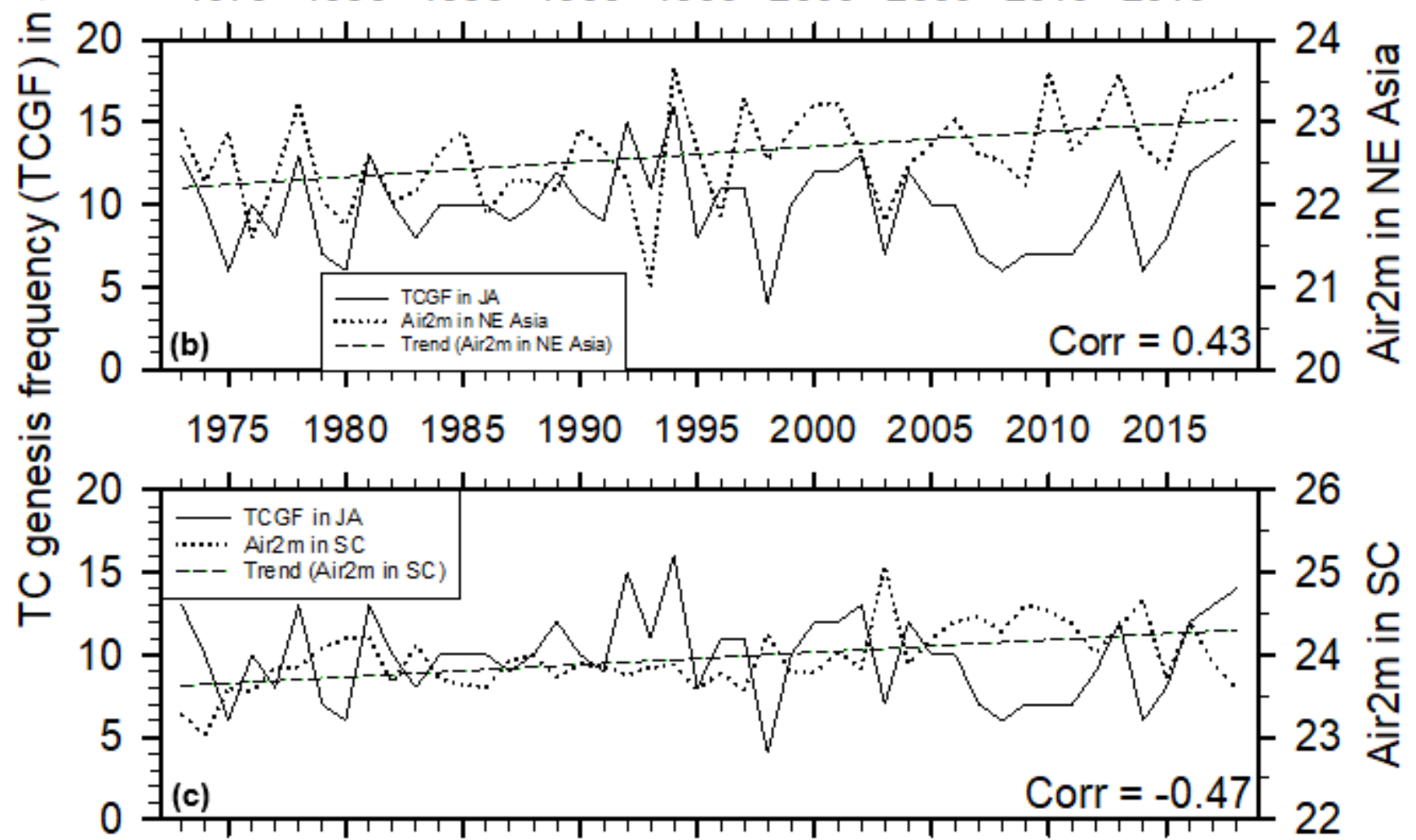

197519801985199019952000200520102015

Figure 2

Time series of tropical cyclone (TC) genesis frequency (TCGF) in the western North Pacific (left), (a) HWD in Korea (left upper panel), (b) air2m in Northeast (NE) Asia (left middle panel), and (c) air2m in South China (SC) (left lower panel) in July-August (JA). 

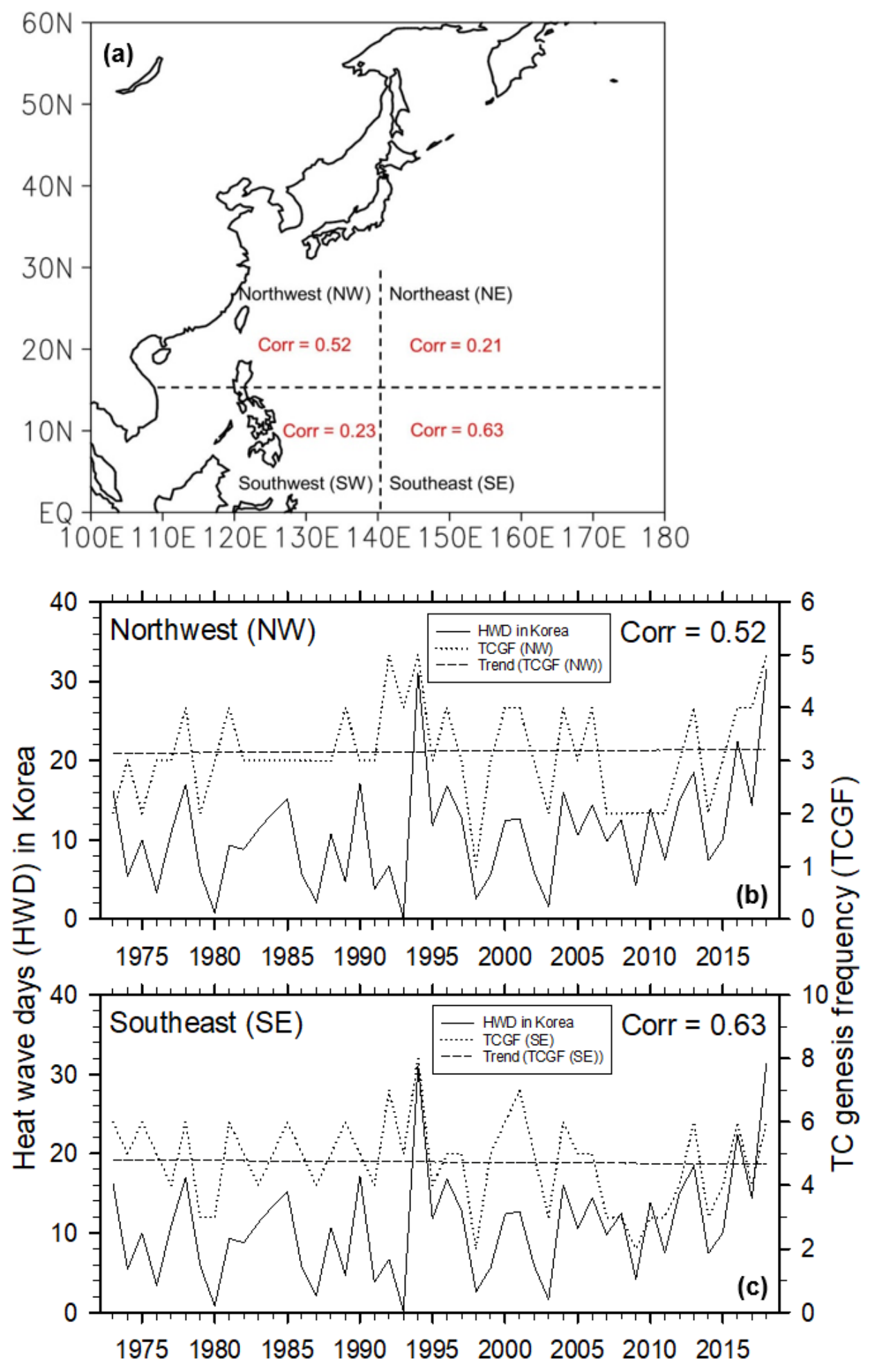

\section{Figure 3}

(a) spatial distribution of correlation coefficients between HWD in Korea and TCGFs in northwest area, southwest area, northeast area, and southeast area over the western North Pacific in JA. Time series of HWD in Korea, (b) TCGF in northwestern area, and (c) southeastern area over the western North Pacific in JA. 
(a) High TCGF years

(b) Low TCGF years

(c) High minus Low TCGF years
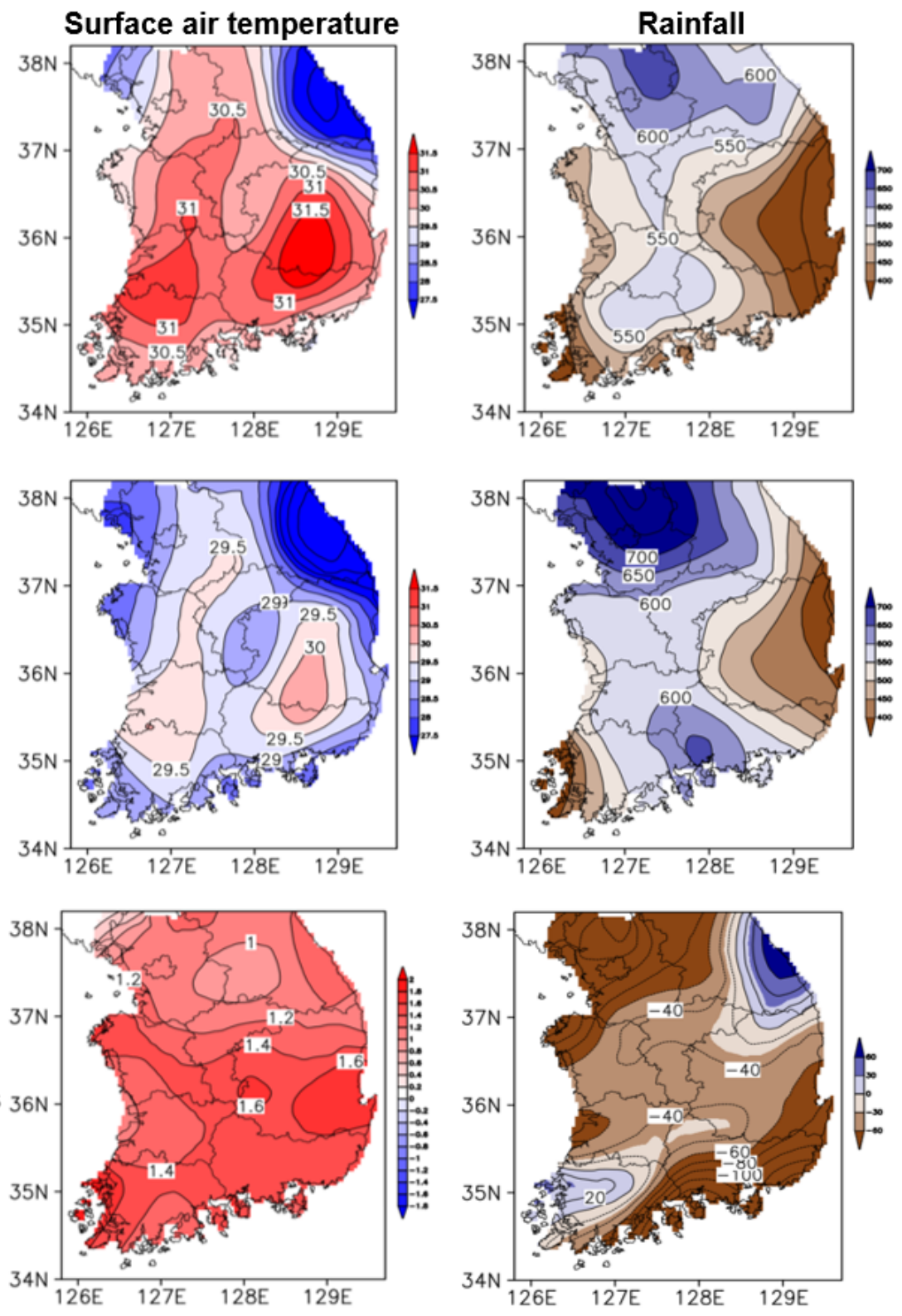

(d)
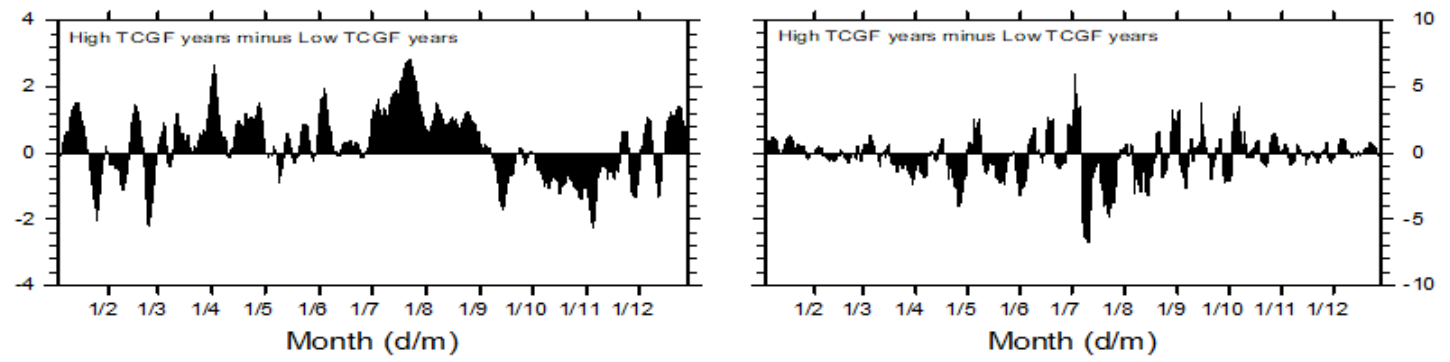

Figure 4

Spatial distributions of surface air temperature (oC) (left panel) and rainfall (mm) (right panel) in (a) high TCGF years, (b) low TCGF years, and (c) high minus low TCGF years in JA. (d) 5-day running mean time series of surface air temperature (oC) (left panel) and rainfall (mm) (right panel) in high minus low TCGF years. 


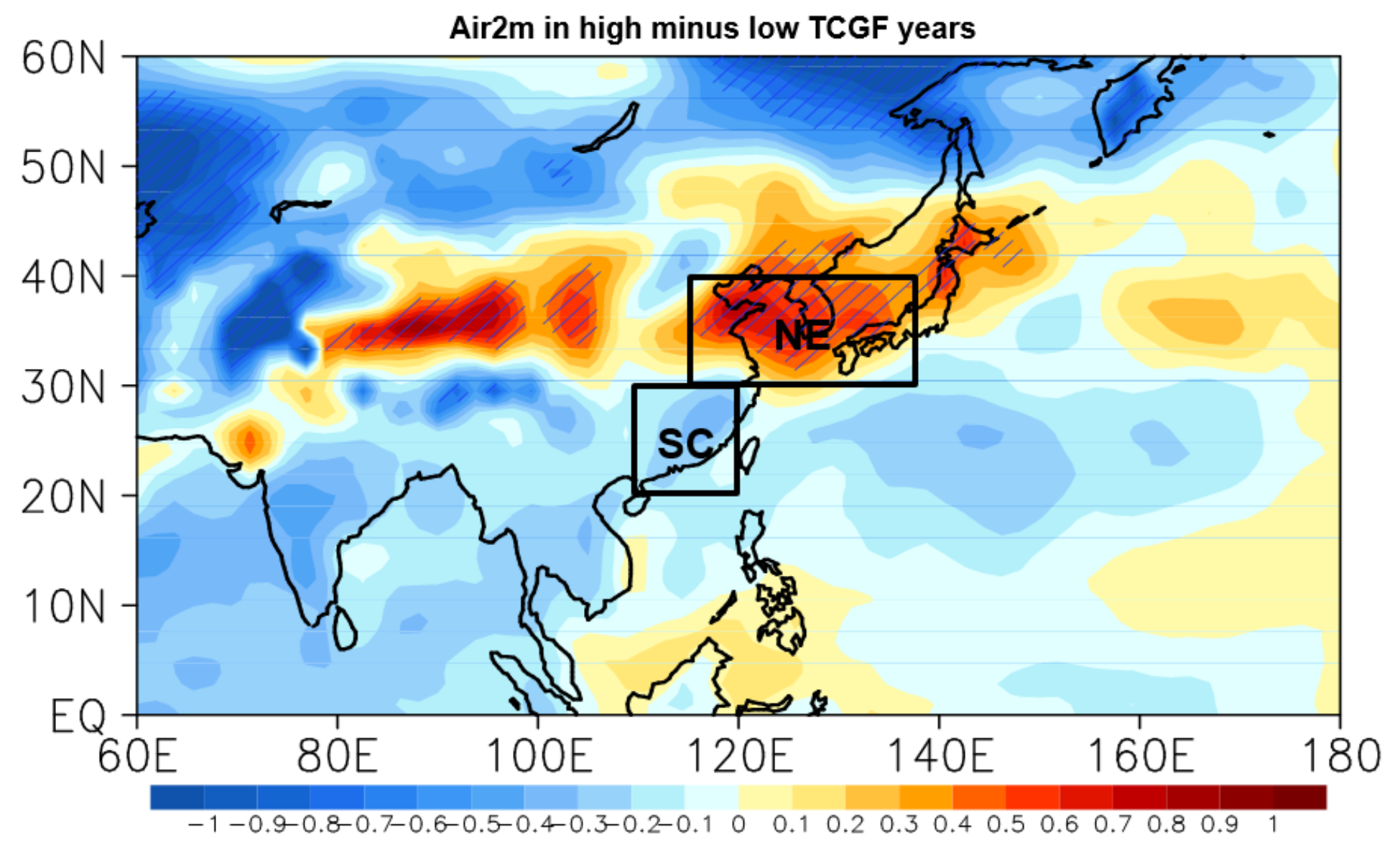

Figure 5

Composite difference in $2 \mathrm{~m}$ air temperature $\left({ }^{\circ} \mathrm{C}\right)$ (air2m) between high and low TCGF years in JA. Hatched areas are significant at the $95 \%$ confidence level. South China (SC) area is $20^{\circ}-30^{\circ} \mathrm{N}, 110^{\circ}-120^{\circ} \mathrm{E}$ and Northeast (NE) Asia area is $30^{\circ}-40^{\circ} \mathrm{N}, 115^{\circ}-140^{\circ} \mathrm{E}$. 
(a) $850 \mathrm{hPa}$
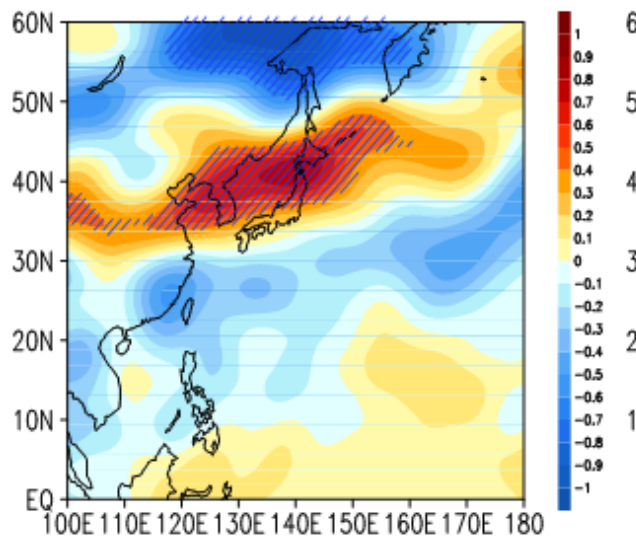

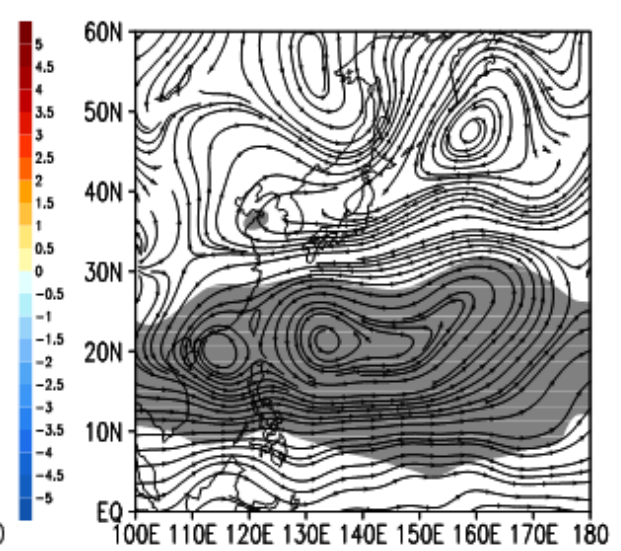

(b) $500 \mathrm{hPa}$
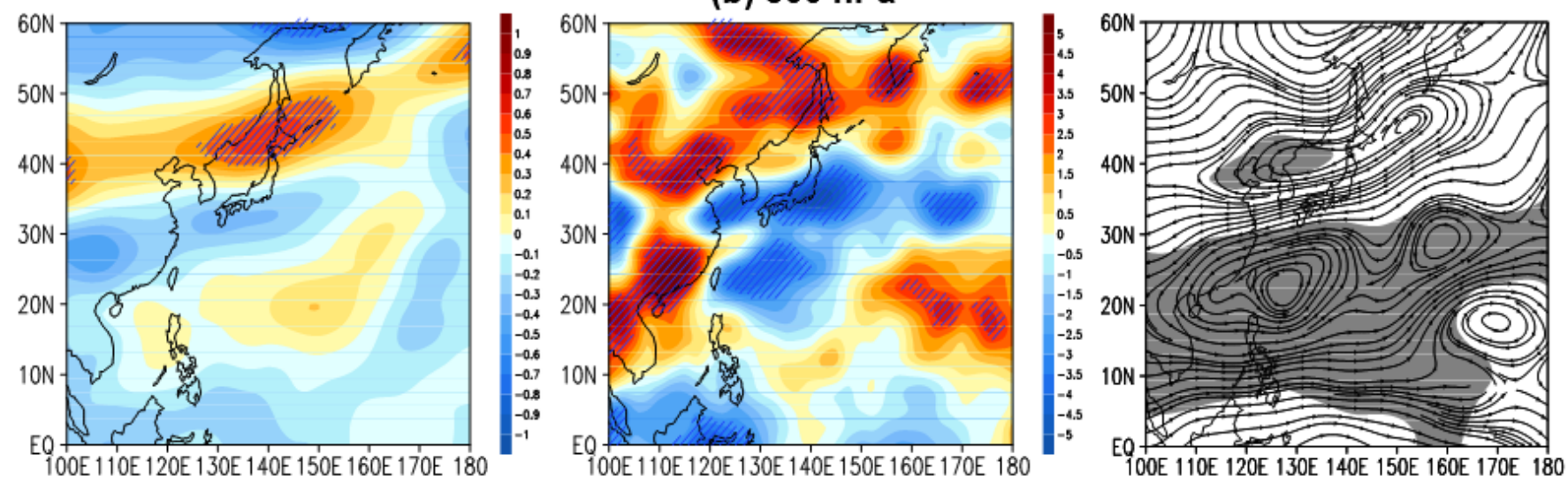

\section{(c) $300 \mathrm{hPa}$}

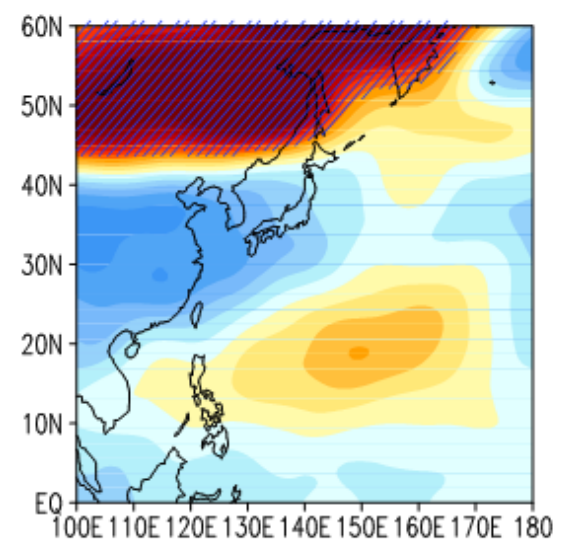

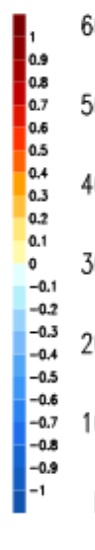

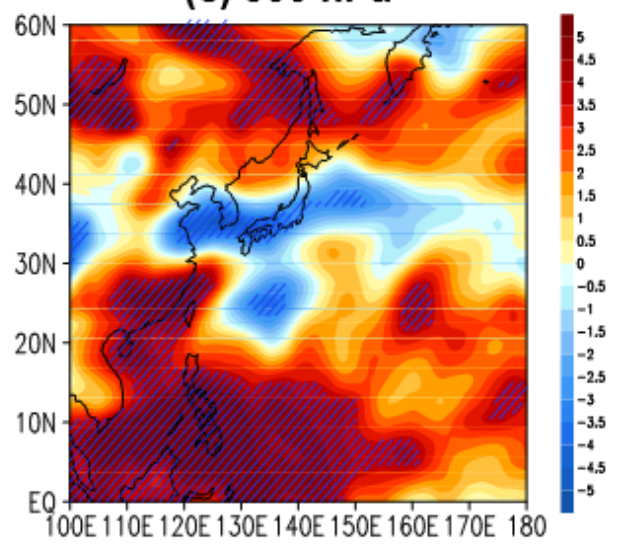

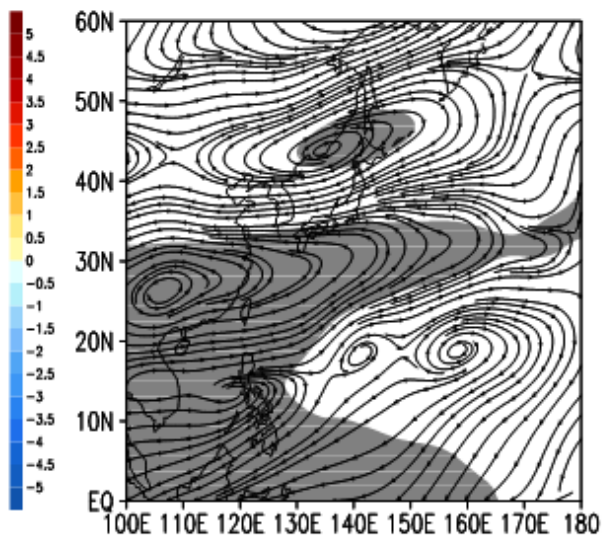

\section{Figure 6}

Composite differences in air temperature (oC) (left panel), relative humidity (\%) (middle panel), and stream flow (right panel) at (a) $850 \mathrm{hPa}$, (b) $500 \mathrm{hPa}$, and (c) $300 \mathrm{hPa}$ between high and low TCGF years in JA. Hatched areas in air temperature and relative humidity and shaded area in stream flow are significant at the $95 \%$ confidence level. 
(a) High TCGF years
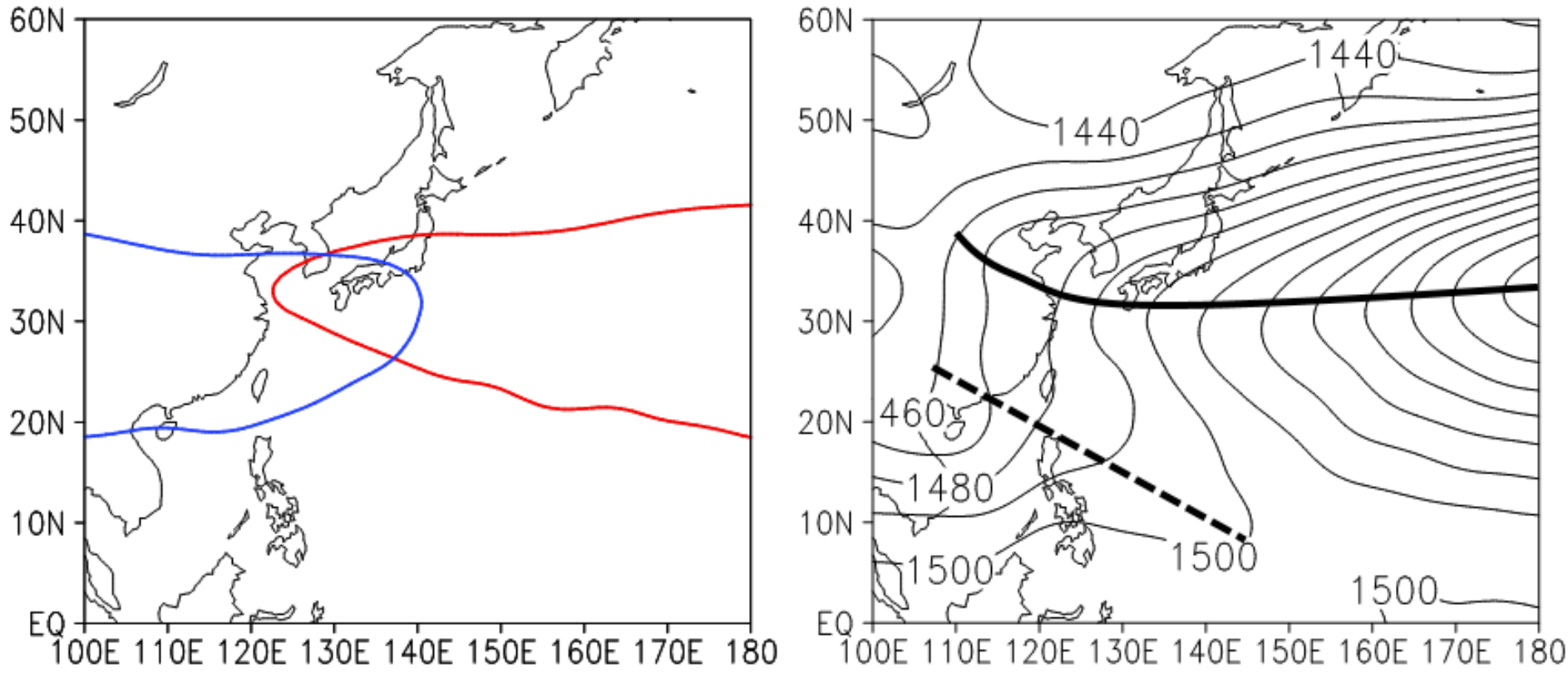

(b) Low TCGF years
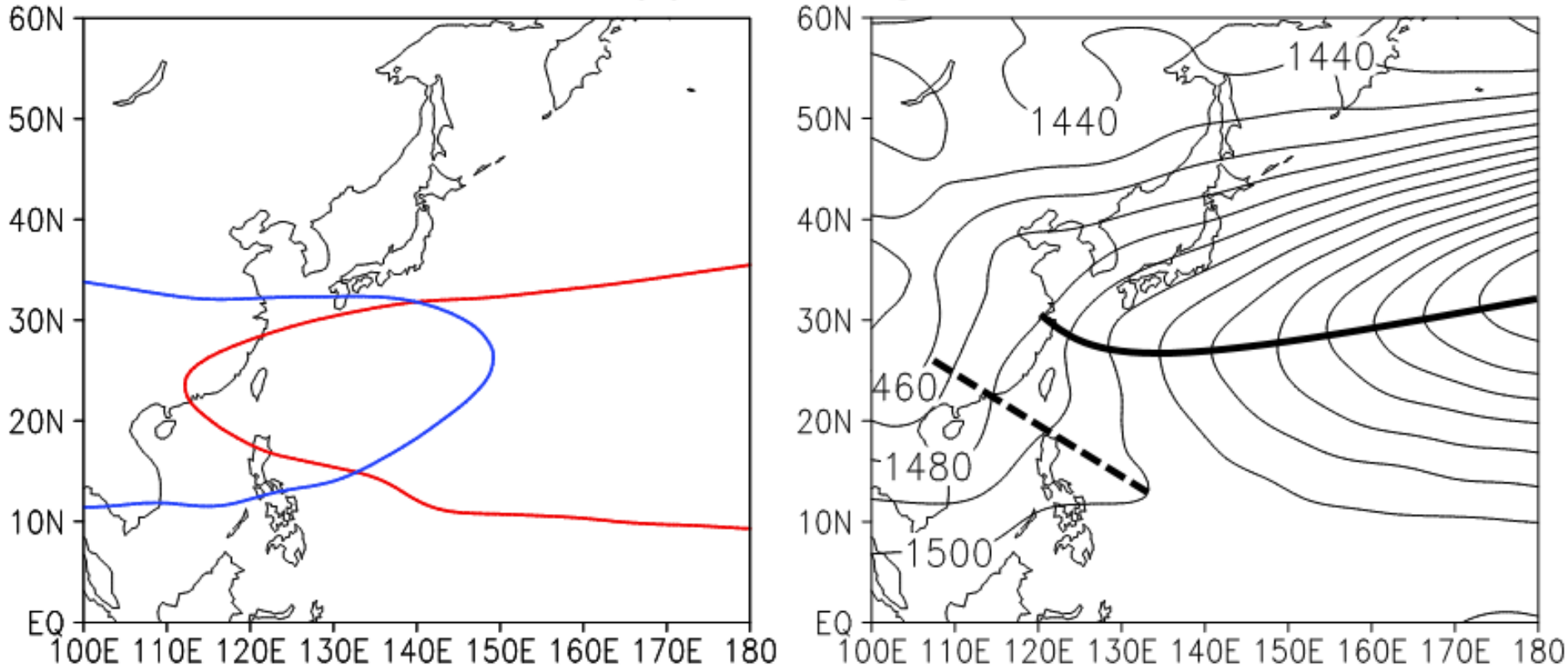

Figure 7

Spatial distributions of western North Pacific subtropical high (WNPSH; 5,870 gpm contour, red line in left panel) and Tibetan high (TH; 12,480 gpm contour, blue line in left panel) in JA and composite maps of $850 \mathrm{hPa}$ geopotential height in (a) high TCGF years and (b) low TCGF years in JA. In (b), dashed and solid lines denote monsoon trough and ridge of WNPSH, respectively. 
(a) Meridional circulation

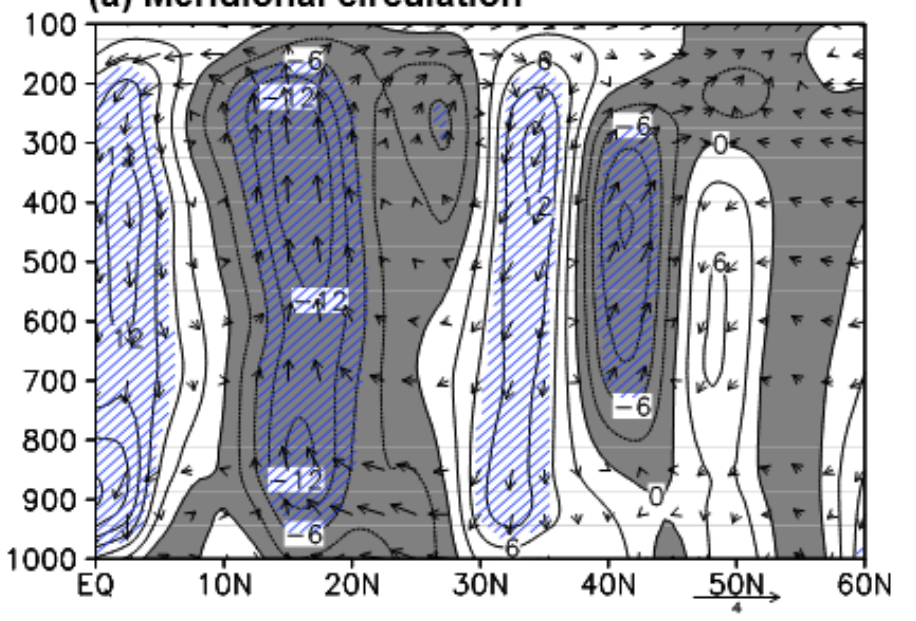

(b) Air temperature

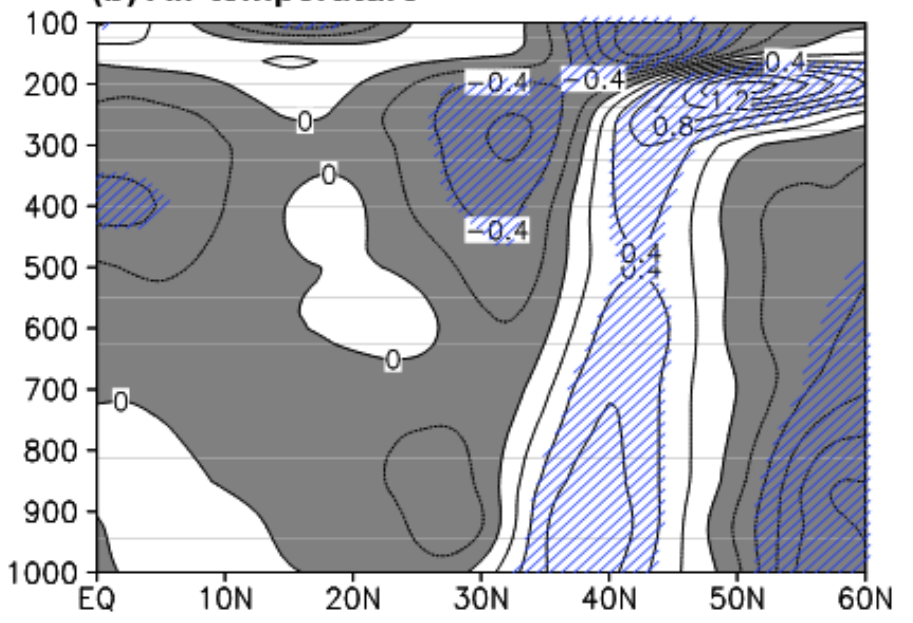

(c) Relative humidity

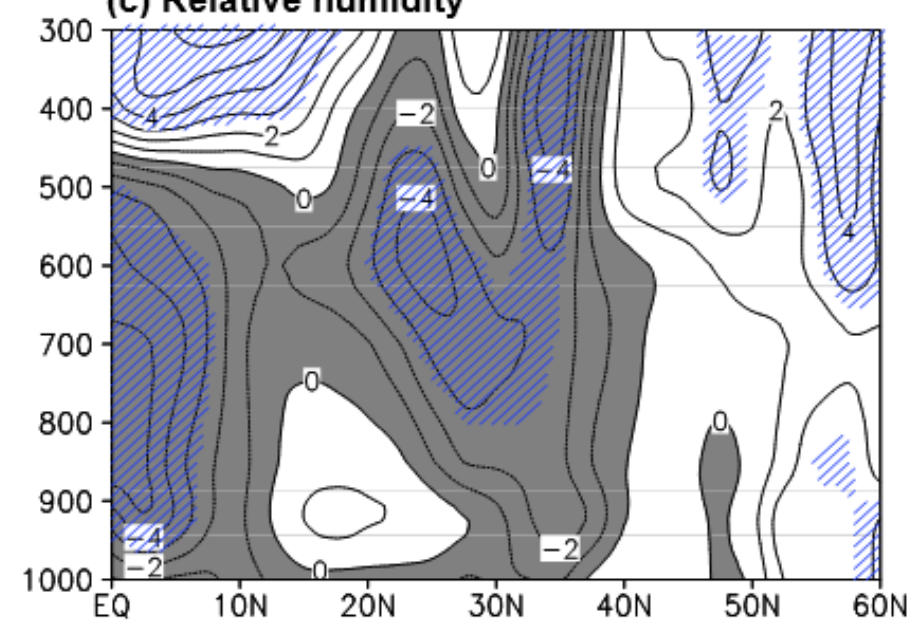

Figure 8

Composite differences of latitude-pressure cross-section of (a) vertical velocity (contours) and meridional circulations (vectors), (b) air temperature, and (c) relative humidity averaged along $120^{\circ}-130^{\circ} \mathrm{E}$ between high and low TCGF years in JA. The values of vertical velocity are multiplied by -100 . Dashed areas are significant at the $95 \%$ confidence level and shaded areas denote negative values. Contour 
intervals are $2-2 \mathrm{hPa} s-1,0.2^{\circ} \mathrm{C}$, and $1 \%$ for vertical velocity, air temperature, and relative humidity, respectively.
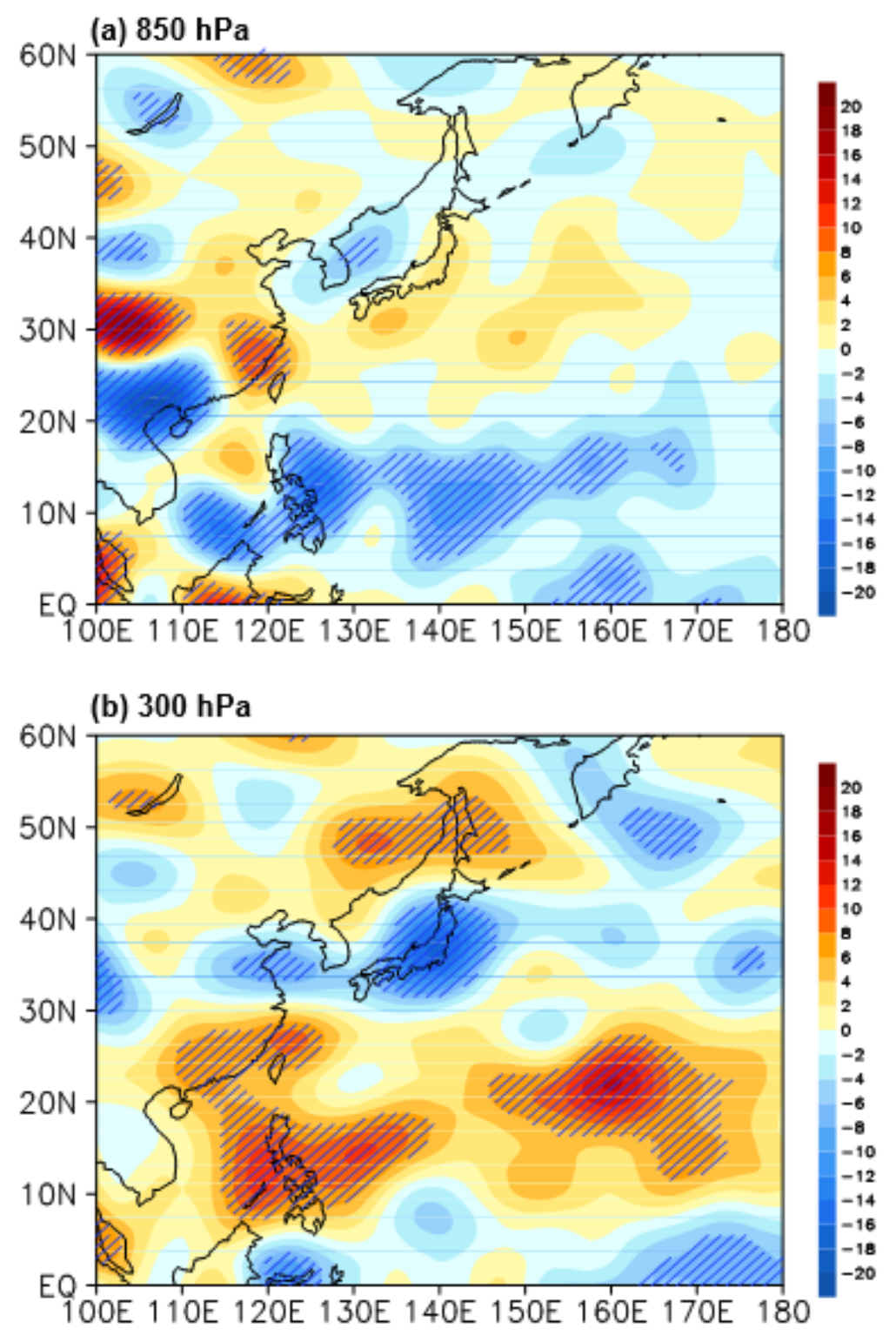

Figure 9

Composite difference in horizontal divergence (unit: s-1*107) between high and low TCGF years at (a) $850 \mathrm{hPa}$ and (b) $300 \mathrm{hPa}$ in JA. Hatched areas are significant at the $95 \%$ confidence level. 


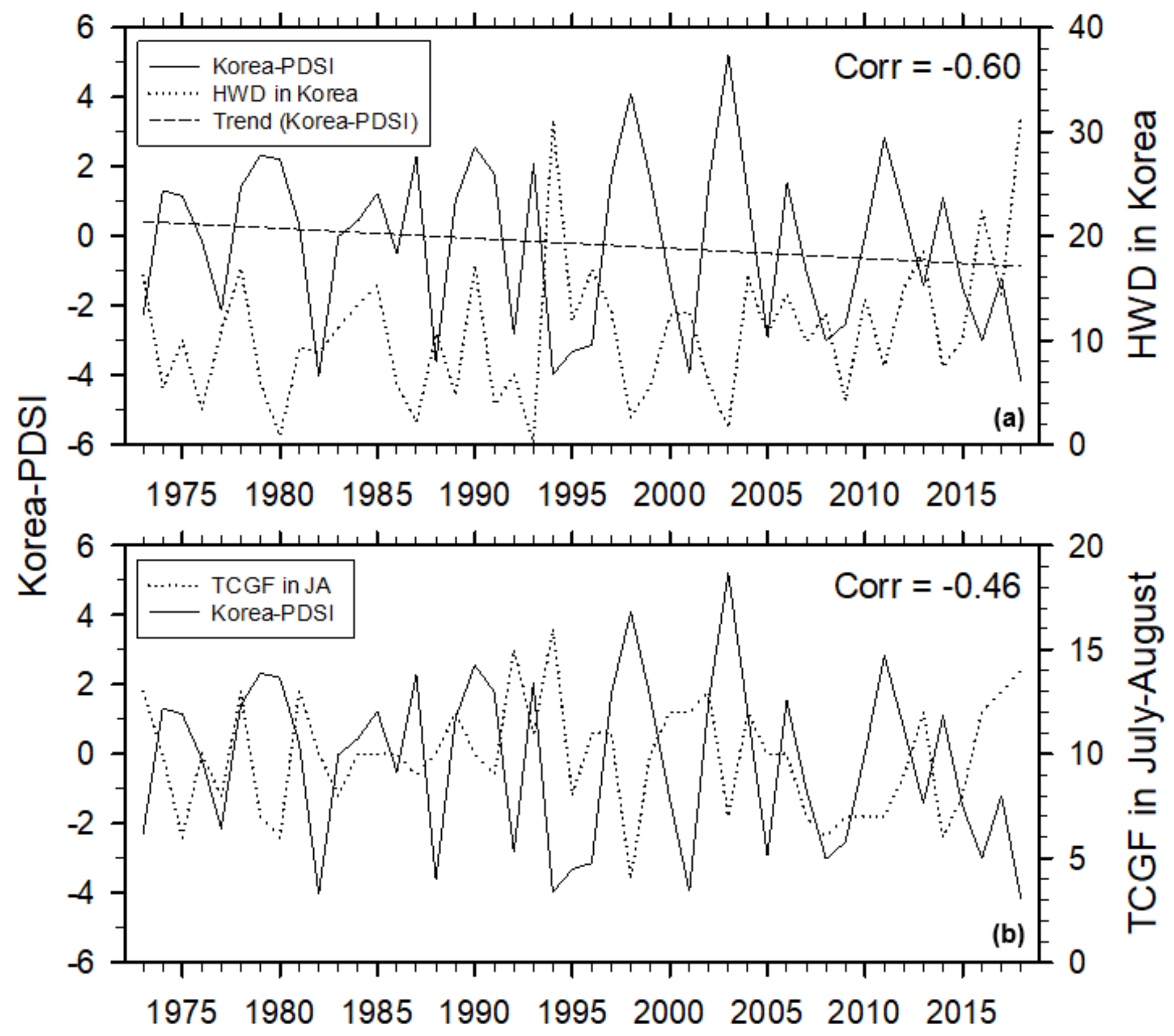

Figure 10

Time series of Palmer Drought Severity index (PDSI) in Korea and (a) HWD in Korea and (b) TCGF in JA. 

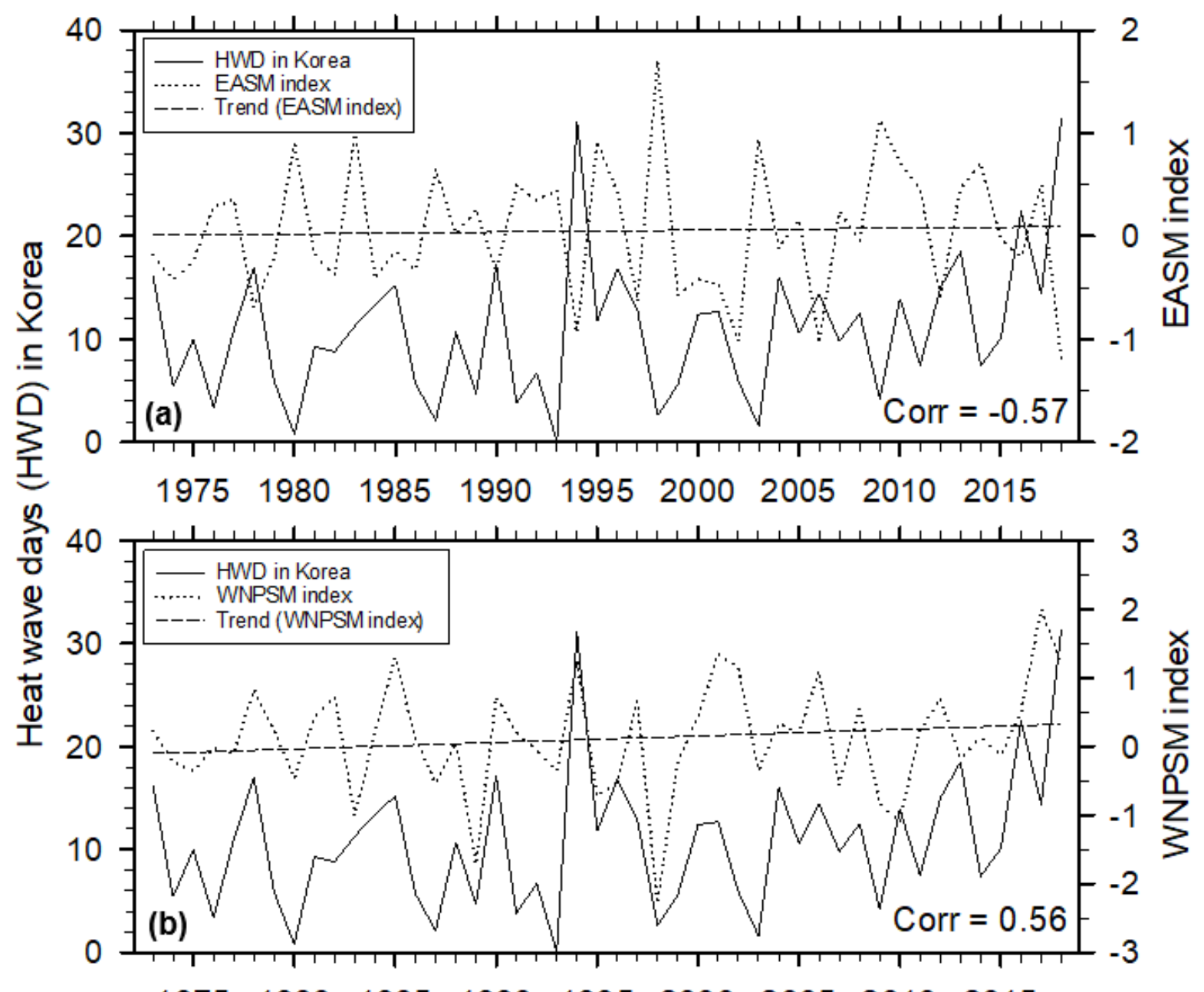

197519801985199019952000200520102015

(c) OLR

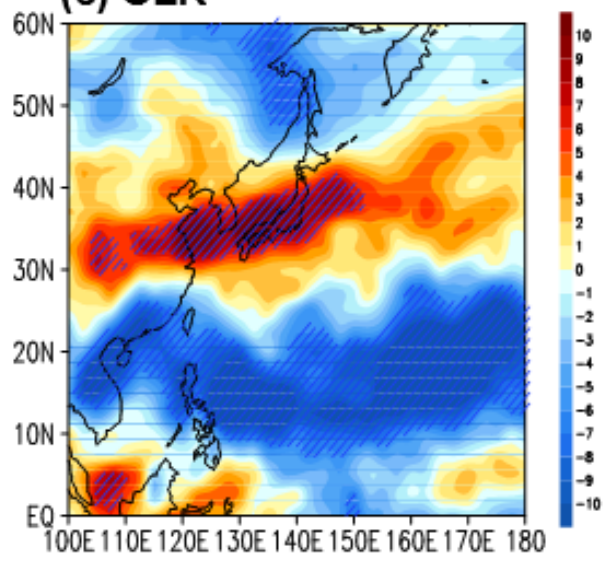

(d) Total cloud cover

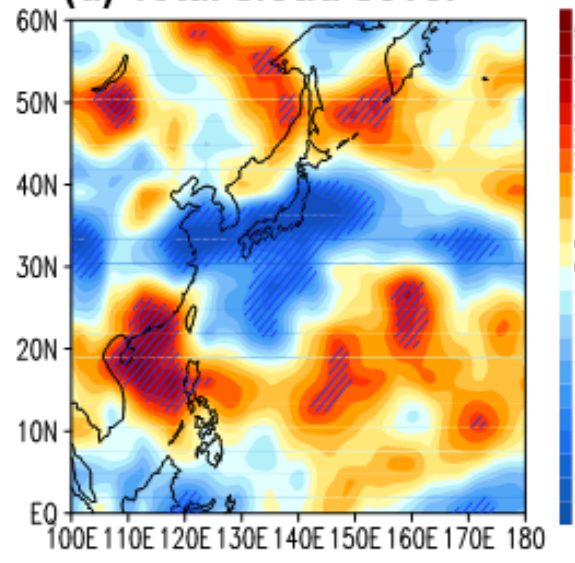

(e) Rainfall

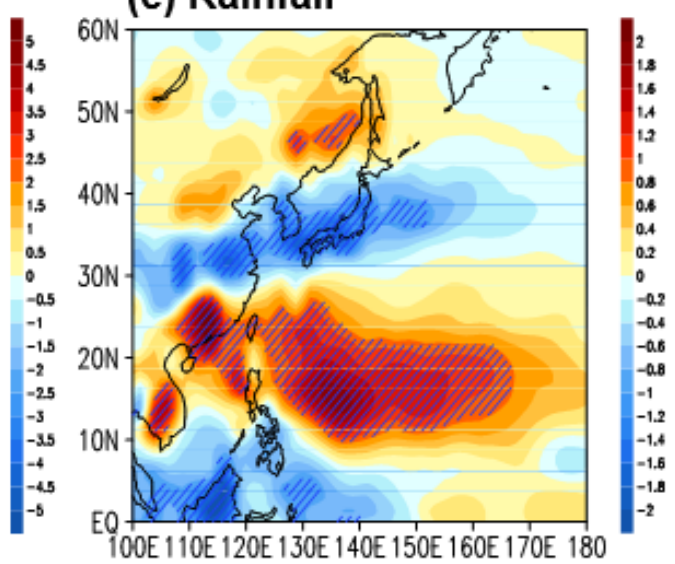

\section{Figure 11}

Time series of HWD in Korea and (a) East Asian summer monsoon (EASM) index and (b) western North Pacific summer monsoon (WNPSM) index. Composite difference in (c) outgoing longwave radiation (OLR; Wm-2), (d) total cloud cover (\%), and (e) rainfall (mm) between high and low TCGF years. In (c), (d), and (c), hatched areas are significant at the $95 \%$ confidence level. 
(a) Sea surface temperature (SST)

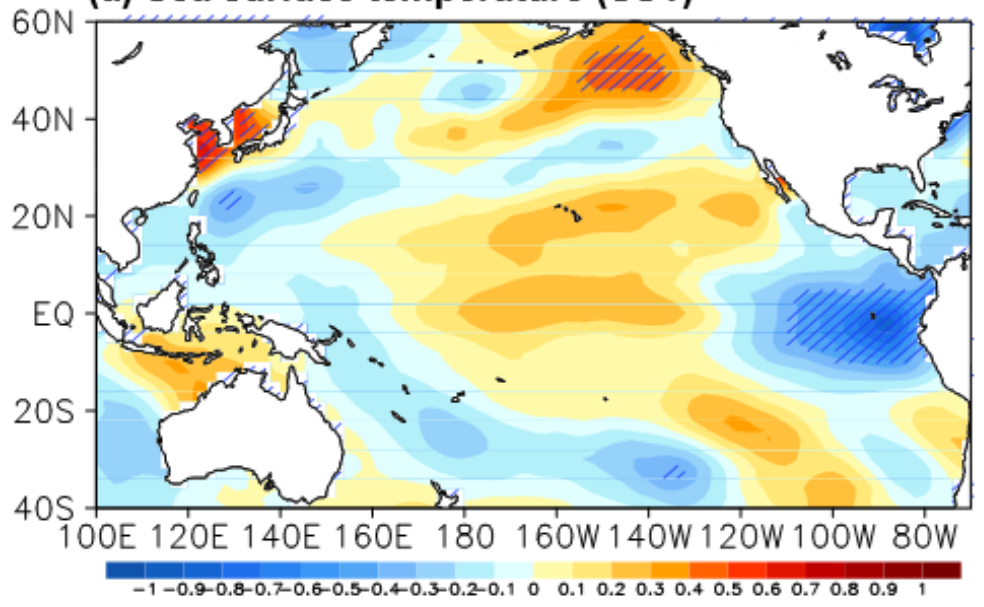

(b) $850 \mathrm{hPa}$ velocity potential (divergent wind)

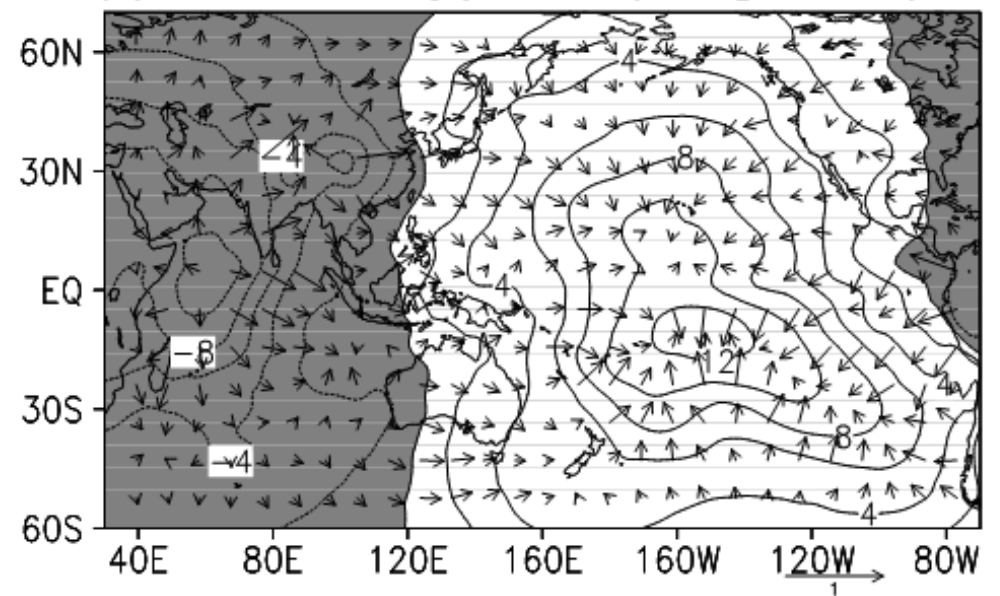

(c) $200 \mathrm{hPa}$ velocity potential (divergent wind)

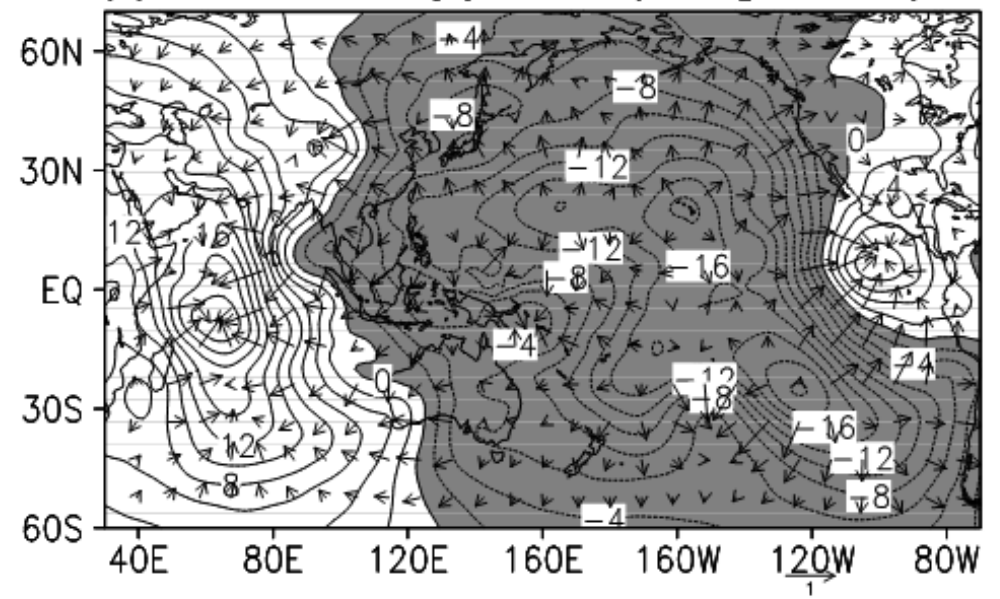

Figure 12

(a) composite difference in SST between high and low TCGF years. In (a), hatched areas are significant at the $95 \%$ confidence level. (b) composite differences in (b) $850 \mathrm{hPa}$ velocity potential and divergent wind and (c) $200 \mathrm{hPa}$ velocity potential and divergent wind between high and low TCGF years. In (b) and (c), shaded areas denote negative anomalies and contour interval is 2 m2s-110-6. 

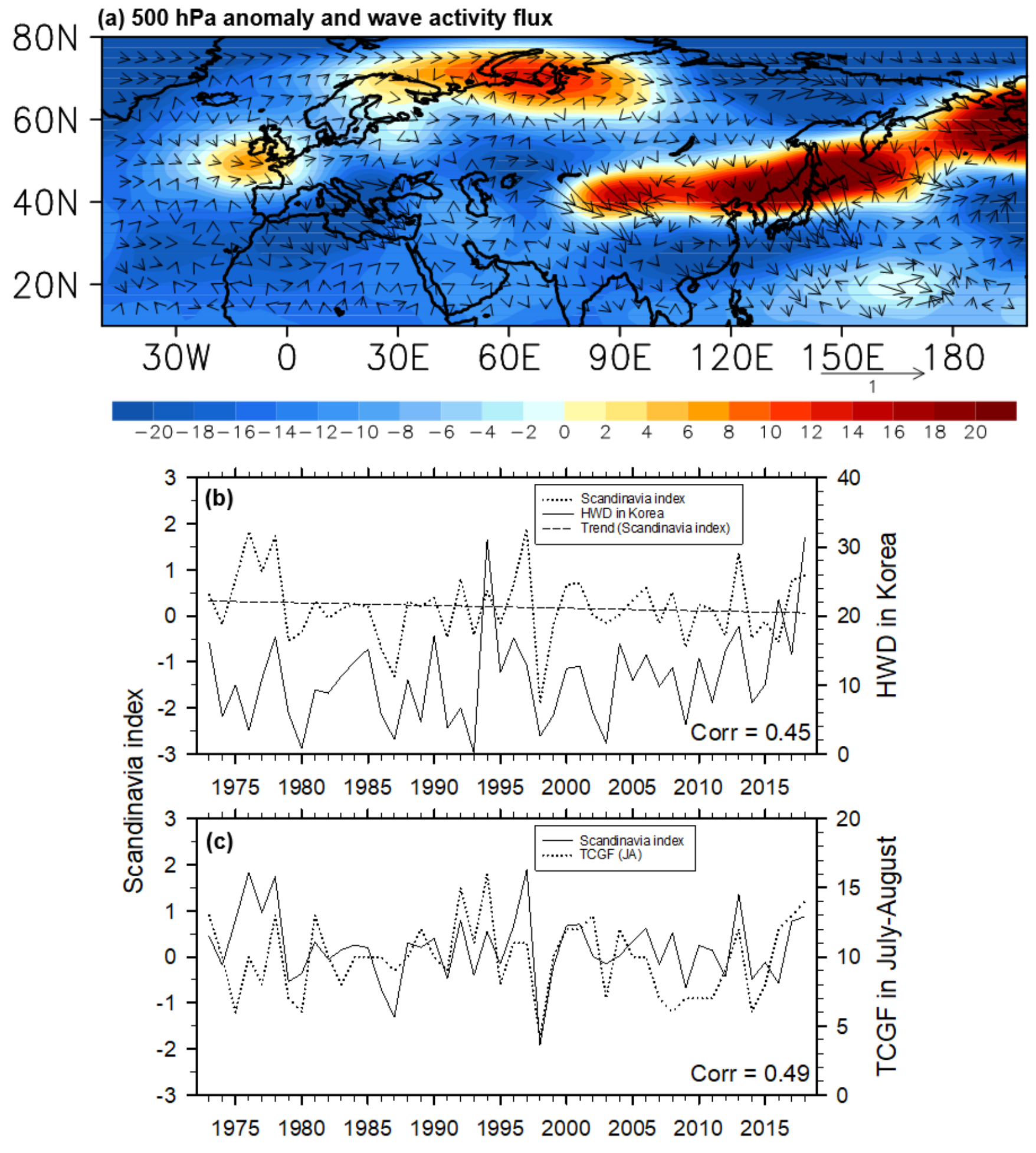

Figure 13

(a) composite differences in $500 \mathrm{hPa}$ geopotential heigh (shaded) and $500 \mathrm{hPa}$ wave activity flux (vector). Time series of Scandinavia index and (b) HWD in Korea and (c) TCGF in JA). 
(a) TC genesis frequency (TCGF)

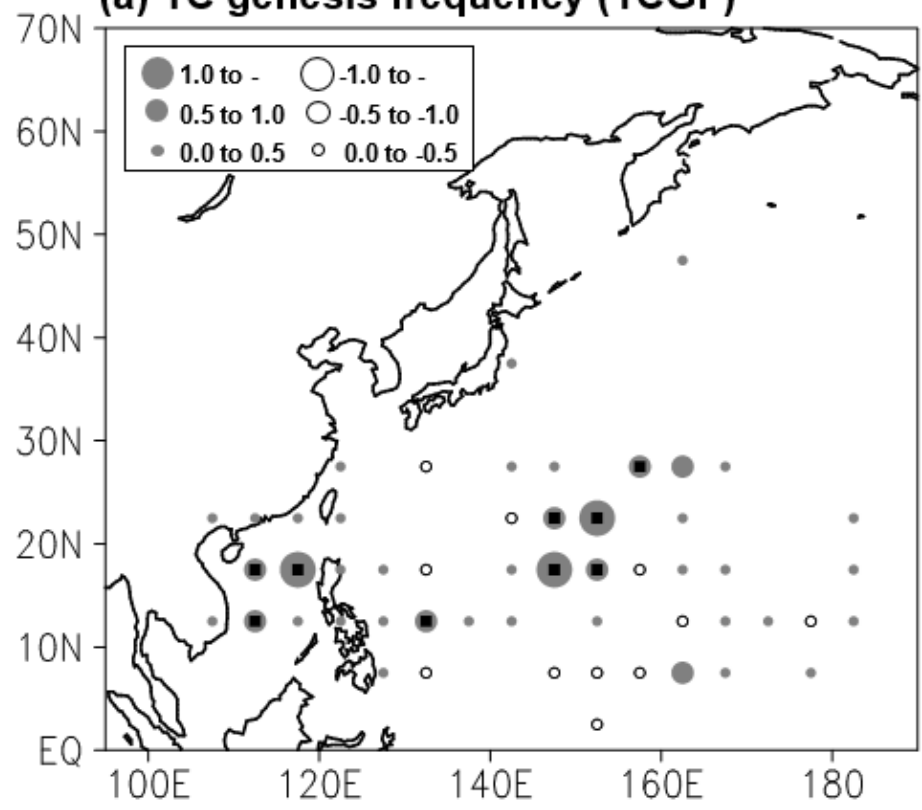

(b) TC passage frequency (TCPF)

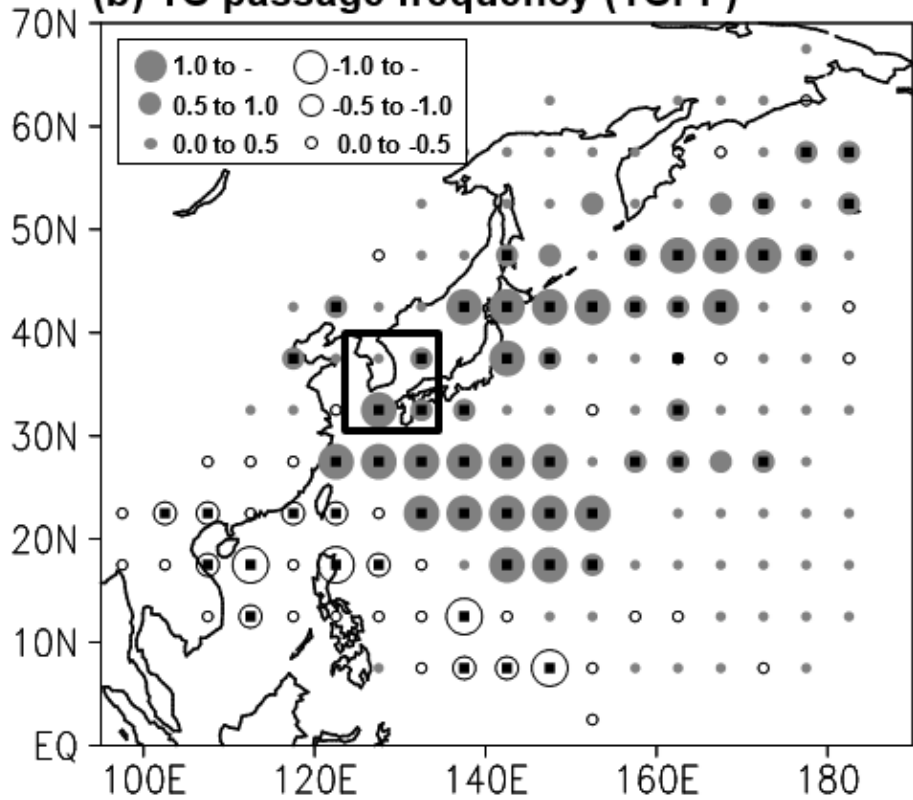

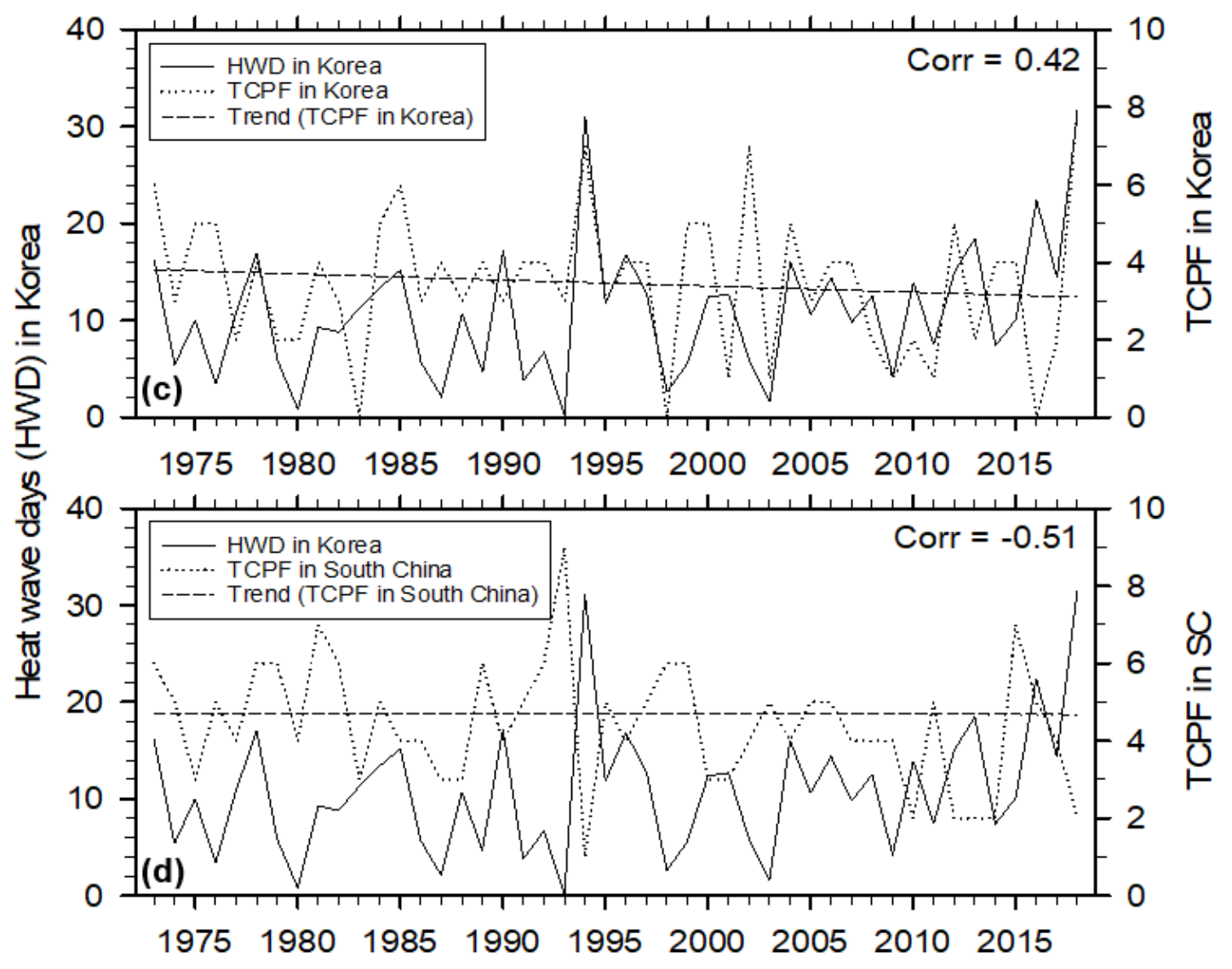

Figure 14

Differences in (a) TC genesis frequency (TCGF) and (b) TC passage frequency (TCPF) between high and low TCGF years. In (a) and (b), small squares inside the circles indicate that the differences are significant at the $95 \%$ confidence level. In (b), square box denotes Korea area $\left(30^{\circ}-40^{\circ} \mathrm{N}, 120^{\circ}-130^{\circ} \mathrm{E}\right)$. Time series of HWD in Korea and (c) TCPF in Korea and TCPF in SC. 

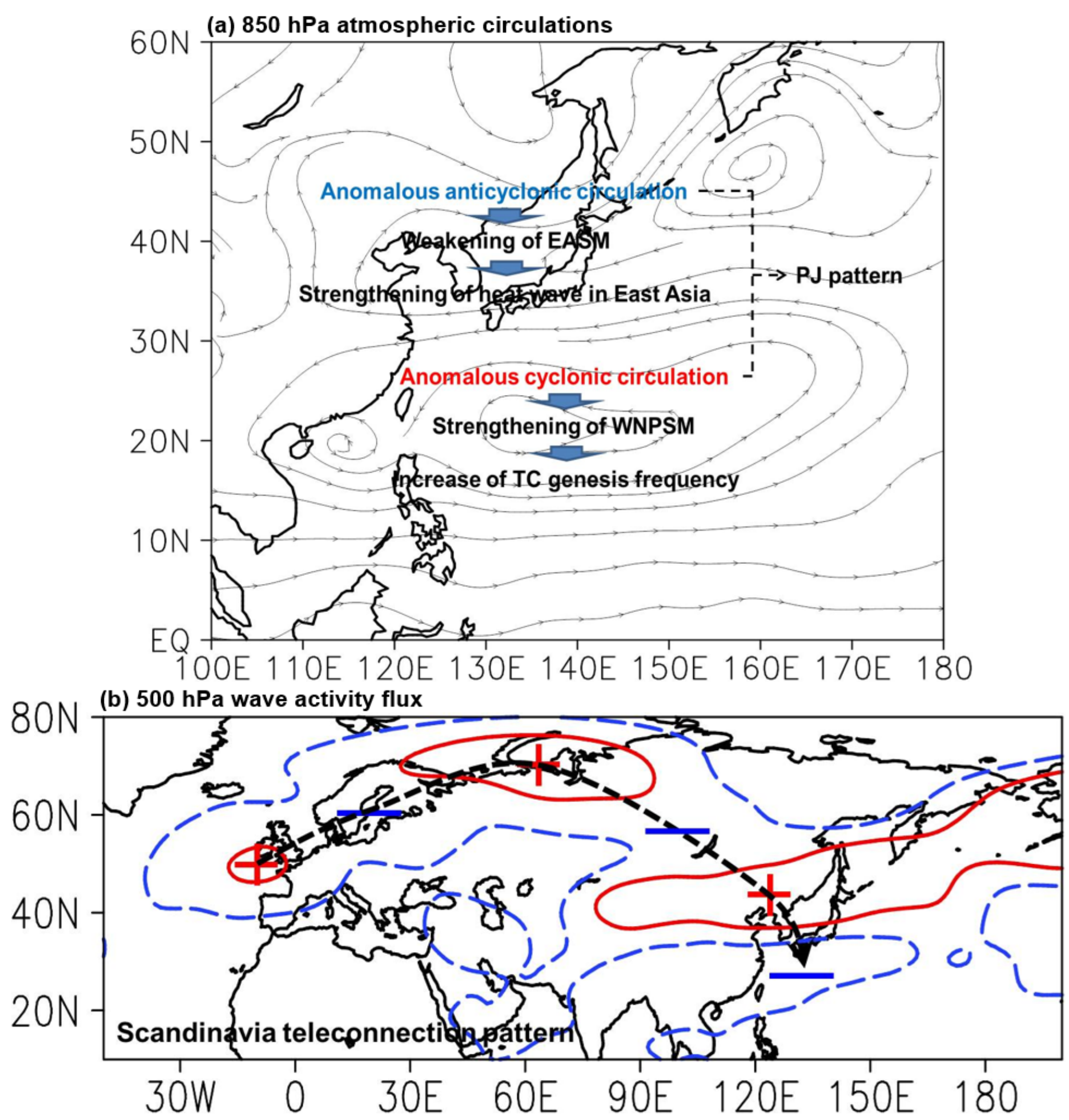

Figure 15

Schematic illustration of (a) $850 \mathrm{hPa}$ anomalous atmospheric circulations and (b) $500 \mathrm{hPa}$ wave activity flux occurring during the high TCGF years. 